\title{
Diamonds in the Rough: Harnessing Tumor-Associated Myeloid Cells for Cancer Therapy
}

\author{
Emile J. Clappaert ${ }^{1,2}$, Aleksandar Murgaski ${ }^{1,2}$, Helena Van Damme ${ }^{1,2}$, Mate Kiss ${ }^{1,2 \dagger}$ and \\ Damya Laoui ${ }^{1,2 * t}$ \\ ${ }^{1}$ Myeloid Cell Immunology Lab, VIB Center for Inflammation Research, Brussels, Belgium, ${ }^{2}$ Lab of Cellular and Molecular \\ Immunology, Vrije Universiteit Brussel, Brussels, Belgium
}

\section{OPEN ACCESS}

Edited by:

Sandra Tuyaerts,

KU Leuven, Belgium

Reviewed by:

Viktor Umansky,

Deutsches Krebsforschungszentrum, Helmholtz-Gemeinschaft Deutscher

Forschungszentren (HZ), Germany

Fabian Benencia

Ohio University, United States

Barbara A. Osborne,

University of Massachusetts Amherst,

United States

*Correspondence:

Damya Laou

dlaoui@vub.be

tThese authors share senior authorship

Specialty section:

This article was submitted to Cancer Immunity and Immunotherapy,

a section of the journal

Frontiers in Immunology

Received: 20 July 2018 Accepted: 10 September 2018 Published: 08 October 2018

Citation:

Clappaert EJ, Murgaski A, Van Damme H, Kiss M and Laoui D

(2018) Diamonds in the Rough: Harnessing Tumor-Associated Myeloid

Cells for Cancer Therapy.

Front. Immunol. 9:2250. doi: 10.3389/fimmu.2018.02250
Therapeutic approaches that engage immune cells to treat cancer are becoming increasingly utilized in the clinics and demonstrated durable clinical benefit in several solid tumor types. Most of the current immunotherapies focus on manipulating $T$ cells, however, the tumor microenvironment (TME) is abundantly infiltrated by a heterogeneous population of tumor-associated myeloid cells, including tumor-associated macrophages (TAMs), tumor-associated dendritic cells (TADCs), tumor-associated neutrophils (TANs), and myeloid-derived suppressor cells (MDSCs). Educated by signals perceived in the TME, these cells often acquire tumor-promoting properties ultimately favoring disease progression. Upon appropriate stimuli, myeloid cells can exhibit cytoxic, phagocytic, and antigen-presenting activities thereby bolstering antitumor immune responses. Thus, depletion, reprogramming or reactivation of myeloid cells to either directly eradicate malignant cells or promote antitumor T-cell responses is an emerging field of interest. In this review, we briefly discuss the tumor-promoting and tumor-suppressive roles of myeloid cells in the TME, and describe potential therapeutic strategies in preclinical and clinical development that aim to target them to further expand the range of current treatment options.

Keywords: tumor-associated dendritic cells, tumor-associated macrophages, myeloid-derived suppressor cells, tumor-associated neutrophils, cancer immunotherapy, tumor microenvironment

\section{INTRODUCTION}

For a long time, tumors were thought to consist mainly of malignant cells, however this view changed in the past decades and tumors are now considered to behave as organ-like structures that contain besides cancer cells a large array of stromal cells. These tumor-infiltrating stromal cells comprise among others, immune cells, fibroblasts, pericytes, and endothelial cells, which closely interact with the cancer cells, forming the tumor microenvironment (TME) (1).

The interactions between the cancer cells and the immune system are initially hostile, resulting in many occasions in a successful eradication of the malignant cells (2). However, due to their rapid evolution, cancer cells can develop immune evasion mechanisms enabling them to avoid immune destruction (1). Furthermore, chronic inflammation caused by the tumor associated immune cells, secreting growth factors, cytokines, chemokines and reactive oxygen species, ultimately leads to an increased survival, growth and heightened rate of mutations in the DNA of the cancer cells (3). The presence of these tumor-promoting immune cells is often associated with an increased resistance 
to cancer therapies (4-8). Nevertheless, some of these tumorassociated immune cells still retain their anti-tumoral properties, the latter being suppressed by several factors produced in the TME (6, 9-12).

Deploying the immune system in anti-cancer therapies enables the specific targeting of (metastatic) cancer cell in the body expressing the specific tumor-associated antigens (TAAs). Most current immunotherapeutic approaches focus on lymphoid cells, particularly on the reactivation of pre-existing anti-tumoral $\mathrm{T}$ cells or adoptive transfer of tumor-specific $\mathrm{T}$ cells. In this respect, several immunotherapeutic strategies already made it to the clinic, such as CAR T-cell therapy or immune checkpoint inhibitors against PD-1, PD-L1, or CTLA-4, which are capable of re-invigorating T-cell responses in the TME (13-16). However, despite their success, de novo or acquired resistance against these therapies is widespread among patients (17), urging for the development of new immune therapies.

Targeting of tumor-associated myeloid cells, which abundantly infiltrate most solid tumors, might provide novel therapeutic approaches for cancer patients and is an emerging field of interest.

In this review, we briefly describe the role of several distinct tumor-associated myeloid cell subsets, i.e., macrophages, dendritic cells, neutrophils and MDSCs, with emphasis on their tumor-promoting and/or tumor-suppressive roles. Subsequently, the potential of myeloid cells in future cancer immunotherapy will be addressed.

\section{MACROPHAGES}

Referred to as "big eaters," macrophages are one of the largest types of leukocytes, specialized in the phagocytosis of dead cells and pathogens. Besides their role in immune surveillance, macrophages are key players in tissue homeostasis maintenance and tissue repair (18). Macrophages are present in all tissues and originate from yolk sac macrophages, fetal liver monocytes and circulating monocytes that colonize the tissues in sequential waves $(19,20)$.

In tumors, macrophages can comprise up to $50 \%$ of the total hematopoietic compartment, negatively correlate with tumor progression and/or clinical outcome in many cancer types (21), with the majority of TAMs originating from circulating monocytes (22). However, certain studies, using orthotopic tumor models, showed that a fraction of the TAMs arises from the tissue-resident macrophages surrounding the tumor (23, 24). Recent evidence in several murine brain tumor models pointed out that the tissue-resident TAMs (microglia in this case) retained some of their tissue-specific traits, resulting in differential transcriptional profiles and activation states between microglia and monocyte-derived macrophages in the TME (23).

Importantly, multiple studies in mice showed that the TME was infiltrated with a heterogeneous monocyte-derived compartment and encompassed at least two molecular and functionally distinct TAM subsets, which populate different tumor microenvironments, namely a M1-like TAM subset, characterized by a more pronounced pro-inflammatory profile and higher expression of MHC-II and co-stimulatory molecules and a pro-angiogenic and immunosuppresive M2-like TAM subset (Figure 1) $(10,25,26)$. The characteristics and emergence of these subsets are discussed elsewhere $(7,22,27,28)$.

It is, however, important to note that this M1/M2 dichotomy is an oversimplified representation of the vast range of activation states macrophages can adopt in vivo (29). Furthermore, recent studies in human tumors question the existence of distinct M1and M2-like TAM subsets (30-32), indicating the need for a revised TAM nomenclature, which could be based on activation states, such as functional or metabolic programming, or by respecting a graded scale rather than separate entities, in line with the spectrum model of macrophage activity.

Two main TAM-based therapeutic strategies have recently gained interest in the fight against cancer: (i) depletion of TAMs through elimination of resident macrophages or inhibition of monocyte/macrophage recruitment to the TME and (ii) repolarization of immunosuppressive M2-like TAMs into antitumor M1-like TAMs. The first strategy is not the major focus of this review and is therefore only discussed briefly.

\section{Depleting TAMs Through Elimination of Resident Macrophages and/or Inhibition of Monocyte/Macrophage Recruitment}

Several molecules were shown to efficiently deplete TAMs from the TME. The tunicate-derived chemotherapeutic molecule trabectedin demonstrates a cytotoxic activity against circulating monocytes and TAMs by activating the apoptotic pathway via TRAIL, which was successfully tested in several murine tumors models. This ultimately resulted in a decreased number of mononuclear phagocytes and an increased infiltration of antitumoral effector T cells in the TME $(33,34)$. Another group of drugs selectively targeting myeloid cells are bisphosphonates, such as clodronate-liposomes $(35,36)$ which induce the apoptotic pathway in TAMs as well. After liposome uptake, clodronate is released intracellularly and converted to a non-hydrolizable ATP analog, ultimately leading to the formation of pore openings in the mitochondrial inner membrane, eventually resulting in apoptosis. Finally, the conventional chemotherapeutic drug doxorubicin, which inhibits topoisomerase II, has been shown to significantly deplete TAMs in mice with orthotopic MMTVWnt1 triple-negative breast carcinoma, when encapsulated in nanoparticles specifically targeting TAMs, i.e., DOX-AS-MPLGA-nanoparticles (37).

In the aforementioned treatment strategies, all TAMs are targeted, hence also depleting M1-like TAMs with potential antitumoral characteristics. Therefore, selectively depleting M2-like macrophages has gained interest. The identification of MMR as a marker for M2-like TAMs, residing in hypoxic tumor areas (10, 25 ), enables the visualization of these pro-tumoral macrophages for diagnostic purposes using anti-MMR Nanobodies in vivo $(38,39)$ and could potentially be coupled to toxic moieties for selective depletion of M2-like TAMs (40).

In order to prevent monocytes from maturing to tumorpromoting TAMs, the inhibition of monocyte recruitment to the TME can also be envisaged. One approach is to interfere with the 


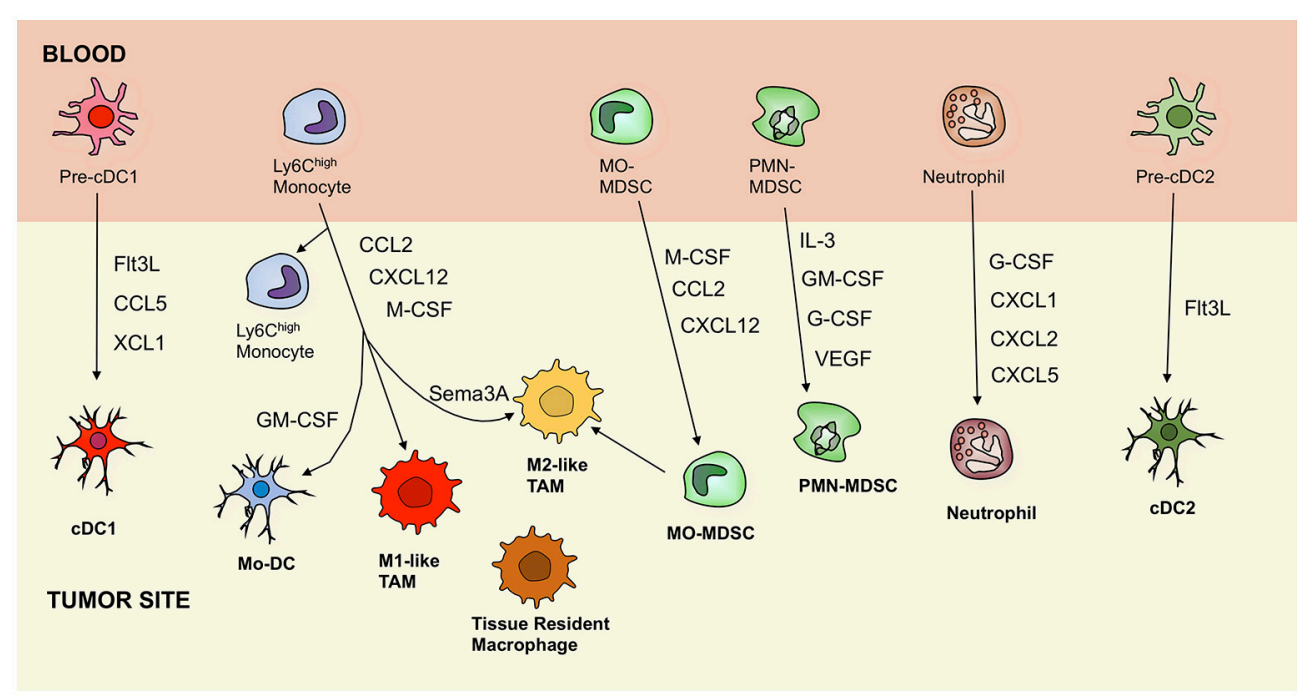

FIGURE 1 | Ontogeny of tumor-associated myeloid cells, including dendritic cells, macrophages, monocytes, myeloid-derived suppressor cells, and neutrophils. Black arrows indicate recruitment pathways that are driven by secreted factors. CDC, conventional dendritic cell; Mo-DC, monocyte-derived dendritic cell; TAM, tumor-associated macrophage; MO-MDSC, monocytic myeloid-derived suppressor cell; PMN-MDSC, polymorphonuclear myeloid-derived suppressor cell; Flt3L, Fms-related tyrosine kinase 3 ligand; CCL5, C-C motif chemokine ligand 5; XCL1, lymphotactin; GM-CSF, granulocyte-macrophage colony-stimulating factor; CXCL12, C-X-C motif chemokine 12; M-CSF, macrophage colony-stimulating factor; Sema3A, semaphorin 3A; IL-3, interleukin 3; GM-CSF, granulocyte-macrophage colony-stimulating factor; G-CSF, granulocyte colony-stimulating factor; VEGF, vascular endothelial growth factor.

CCL2/CCR2 axis, using an anti-CCL2 antibody (41) or bindarit, which inhibits CCL2 synthesis (42). Another important regulator of monocyte recruitment toward the TME is the CSF-1 receptor, whose inhibition leads to macrophage depletion in several murine and human tumors (43-45). Moreover, CSF-1R blockade using monoclonal antibodies or small molecule inhibitors not only leads to a reduced attraction of monocytes to the tumor, but also to the preferential differentiation of monocytes toward M1 TAMs, resulting in a higher intratumoral M1/M2 ratio in mice $(46,47)$. In addition, inhibition of either CCR2 or CSF$1 \mathrm{R}$ has been shown to decrease the chemotherapy-resistance of pancreatic tumors and to increase the T-cell mediated anti-tumor immune response in mice (48).

\section{Reprogramming of the TAM Phenotype}

Enforcing M1 programming of TAMs may reduce their tumor-promoting functions and help stimulate anti-tumor immunity, opening a new field in immunotherapy aiming at the repolarization of the M2-like TAMs to M1-like TAMs (Figure 2) $(22,49)$.

\section{Inhibition of Intracellular Signaling Pathways}

A promising candidate for the repolarization of TAMs is the selective inactivation of phosphatidylinositol-3-kinase $\gamma$ $(\mathrm{PI} 3 \mathrm{~K} \gamma)$. This intracellular kinase has been shown to induce a transcriptional program via Akt and mTOR signaling ultimately leading to immune suppression in the TME (50). Inhibiting PI3K $\gamma$ genetically or via small molecules (TG100-115 or IPI549) resulted in decreased tumor growth and prolonged survival in several murine tumor models, including head and neck squamous cell carcinoma, lung carcinoma and spontaneous breast carcinoma models. TAMs from mice lacking PI3K $\gamma$ showed increased levels of MHC-II and pro-inflammatory cytokines and were less immunosuppressive, which resulted in a restored $\mathrm{CD}^{+}$T-cell activation and cytotoxicity (50). In 4T1 breast carcinoma and B16-GM-CSF melanoma models, the inhibition of PI3K $\gamma$ by the small molecule inhibitor IPI-549, significantly improved the T-cell function and reduced immune suppression by increasing the M1/M2 ratio. Furthermore, in combination with PD-1 and CTLA-4, IPI-549 resulted in complete remission in $30 \%$ of the $4 \mathrm{~T} 1$-bearing and $80 \%$ of B16-GM-CSF-bearing mice (51). Another key regulator of human M2 TAM gene expression is hematopoietic cell kinase (HCK), a member of the Src family kinases. Poh et al. showed that high HCK expression and activation correlated with a reduced survival of colorectal cancer patients and the preferential accumulation of M2-like TAMs respectively. Pharmacological inhibition or genetic reduction of HCK activity suppressed M2-like TAM activation and the growth of colon cancer xenografts, making HCK a promising target for cancer therapy (52). Finally, the inhibition of a group of histone deacetylases, HDAC class IIa, by a specific inhibitor, TMP195, reduced tumor burden and pulmonary metastasis by modulating the TAM phenotype in the murine MMTV-PyMT breast cancer model, and enhanced chemo-and T-cell checkpoint blockade therapy (53).

\section{Toll-Like Receptor Agonists}

Toll-like receptor (TLR) agonists have been shown to be capable of stimulating the repolarization of M2-like TAMs toward M1like TAMs, and therefore entail a promising future therapy. An example of such a ligand is the TLR7/8 agonist, 3M-052, 


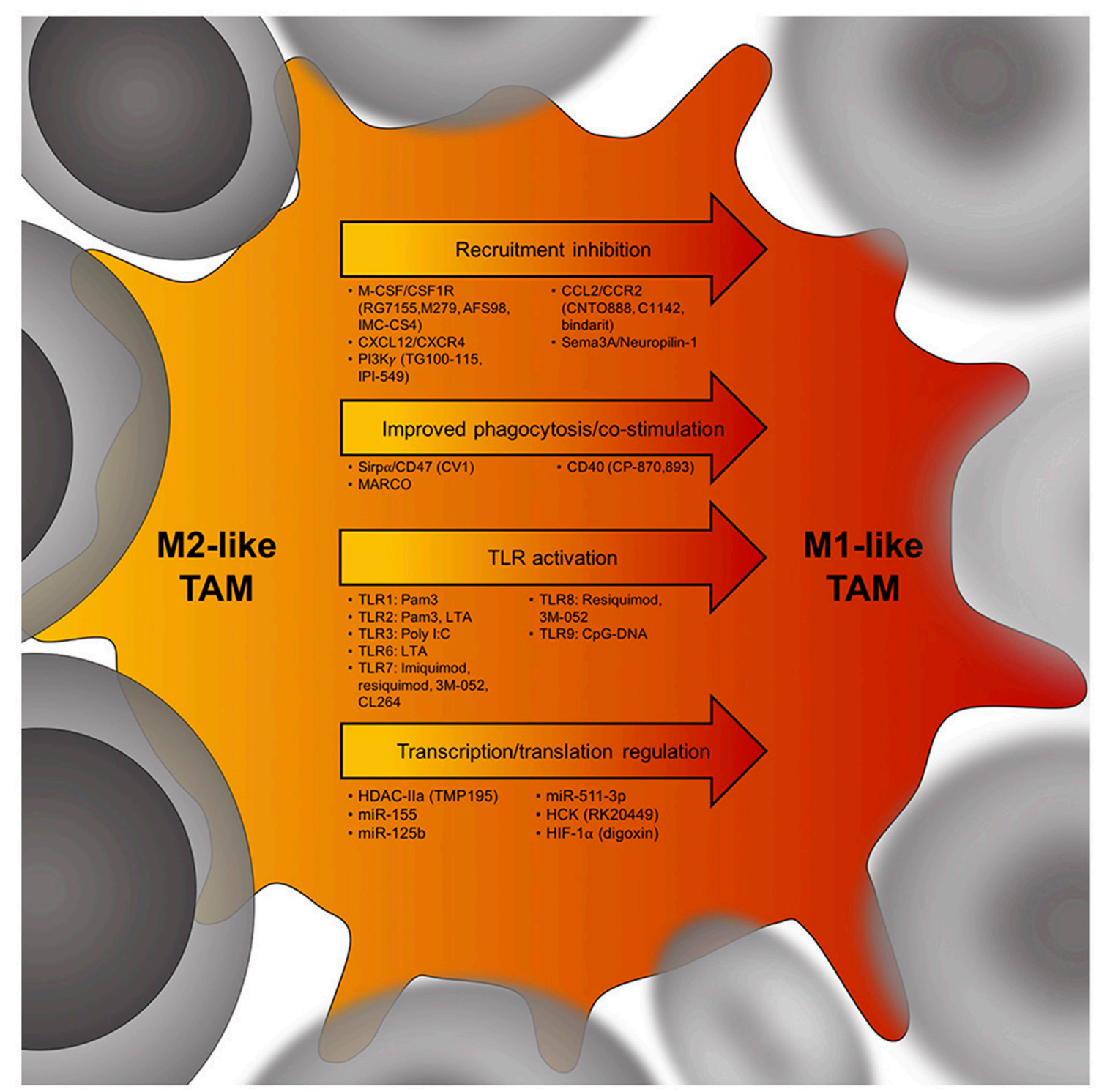

FIGURE 2 | Potential targets to skew the TAM phenotype from an immunosuppressive M2-like TAM (yellow) to an anti-tumor M1-like TAM (red). Cancer cells are in gray, arrows indicate potential targets to induce a TAM phenotype shift within tumors. Below each arrow are specific targets that could influence M2-like TAM phenotypes. M-CSF, macrophage colony-stimulating factor; CSF1R, colony stimulating factor 1 receptor; CXCL12, C-X-C chemokine ligand 12; CXCR4, C-X-C chemokine receptor 4; PI3K $\gamma$, phosphatidylinositol-3-kinase $\gamma$; CCL2, C-C chemokine ligand 2; CCR2, C-C chemokine receptor 2; Sema3A, semaphorin 3A; Sirp $\alpha$, signal regulatory protein alpha; MARCO, Macrophage receptor MARCO; CD40, cluster of differentiation 40; TLR, toll-like receptor; HDAC-Ila, histone deacetylase Ila; miR155, microRNA 155; HCK, proto-oncogene HCK; HIF-1 $\alpha$, hypoxia-inducible factor 1-alpha.

which stimulated M2 to M1 polarization upon intratumoral injection. This approach resulted in a significant decrease of murine B16-F10 melanoma tumor growth through an elevated M1 phenotype-shifted macrophage infiltration with additional activation of $\mathrm{CD}^{+} \mathrm{T}$ cells, B cells, and pDCs. When used in combination with anti-PD-L1 and anti-CTLA4 antibodies, cytotoxicity of TAMs and $\mathrm{CD}^{+} \mathrm{T}$ cells in the same melanoma model was potentiated (54). One of the TLR7 ligands, imiquimod, has been approved by the US Food and Drug Administration to topically treat early skin cancers. The use of imiquimod not only resulted in an inhibition of tumor growth, but also in complete regression of murine TSA mammary tumors, when used in combination with radiotherapy or low dose of cyclophosphamide (55). Another agonist of TLR7 and TLR8, namely 848 or resiquimod, loaded into $\beta$-cyclodextrin nanoparticles induced a functional re-orientation of the TME, in which the M2-like TAMs shifted toward a M1-like TAM phenotype, reducing tumor growth in multiple murine tumor models (56).

The use of a dsRNA analog, poly I:C, which is a potent TLR3 agonist, resulted in lewis lung carcinoma (LLC) regression in mice through the increased presence of tumor-suppressive 
M1-like TAMs (57). Strikingly, already $1 \mathrm{~h}$ after intraperitoneal injection, TNF- $\alpha$ levels increased, leading to the subsequent decrease of LLC tumor growth (57). The TLR9 agonist CpGDNA, was able to induce reprogramming of TAM from a M2-like to a M1-like phenotype, alone or in combination with an antiIL-10R Ab when injected intratumorally in $4 \mathrm{~T} 1$ breast tumorbearing mice (58). In addition to the repolarization of TAMs, this molecule was able to stimulate a cytotoxic T-cell response in the murine EG7-OVA lymphoma model (59).

Aside from the aforementioned strategies, combination therapies using both TLR agonists and immune checkpoint inhibitors have also been shown to be beneficial. Intratumoral injections of TLR7 and TLR9 agonists [1V270 and SD-101(CpG), respectively] alongside with systemic administration of anti-PD1 mAbs successfully suppressed tumor growth in murine models of head and neck squamous cell carcinoma (60). Regression was not only observed at the primary tumor site, but distant tumors were suppressed as well, with a clear increased ratio of M1-like to M2-like TAMs (60). In addition, the efficacy of antiPD-1 treatment in athymic nude mice implanted with human osteosarcoma relied on the presence of macrophages in the tumor. As such, anti-PD-1 treatment led to a higher activation of M1 macrophages due to repolarization from M2 TAMs, likely due to STAT3 signaling blockade (36).

Müller et al. tested a whole panel of TLR agonists with or without co-administration of IFN $\gamma$ in an in vitro cancer cell growth inhibition assay using bone marrow-derived macrophages. Their results pointed out that IFN $\gamma$ and the TLR agonists [LPS, poly(I:C), TLR1/2 agonist Pam3, TLR2/6 agonist LTA, TLR7 agonist CL264, and TLR9 agonist CpG] acted in synergy to induce macrophage tumoricidal activity and production of both $\mathrm{NO}$ and pro-inflammatory cytokines. These results suggest that IFNy secretion in the TME may be an important factor that determines the effectiveness of TLR agonists (61).

Analogous to the activation of TLRs, bacterial species can be inoculated in the TME, resulting in acute inflammation and M1like TAM activation. Bacteria mediated tumor therapy has been extensively reviewed elsewhere $(62,63)$.

\section{TAM Repolarization and miRNAs}

One of the post-transcriptional regulators that mediate differentiation of monocytes into either M1-like or M2-like TAMs are miRNAs, small non-coding pieces of RNA of approximately 20-25 nucleotides. While their exact functions in macrophage polarization are yet to be fully elucidated, some have already gained interest for future therapies.

A gain of function study showed that overexpressing miR155 in M2-activated macrophages led to repolarization of these cells into proinflammatory M1-like macrophages (64). Through the regulation of FGF2 expression, miR-155 was able to decrease tumor progression, making it a potential target in future immunotherapy (65). Overexpression of another miRNA, namely miR125b, using a viral vector, proved to promote the M1like activation, leading to an increased cytotoxic activity against EL4 cancer cells in vitro and in vivo (66). Transfecting miR125b using CD44 targeting nanoparticles led to a 6 fold increase in the M1/M2 ratio in a mouse model of non-small cell lung cancer (67). Another strategy involved the enforced expression of miR-511-3p, which is encoded by MRC1 genes, in TAMs, resulting in a decreased protumoral gene signature of MCR1 $(\mathrm{MMR})^{+}$TAMs and inhibited murine LLC tumor growth (68).

Finally, the importance of miRNAs in the differentiation of macrophages in the TME was demonstrated by Baer et al. in mice, where the inactivation of the miRNA-processing enzyme DICER in TAMs promoted the intratumoral expansion of M1-like TAMs, with a pronounced IFN- $\gamma /$ STAT1 transcriptional signature and the concurrent demise of M2-like TAMs. The TAM's phenotype switch was associated with enhanced tumor infiltration by cytotoxic T-cells (CTLs) and IFN- $\gamma$ production, MC38 tumor inhibition and, importantly, increased tumor responsiveness to PD1 checkpoint blockade (69).

\section{Tumor Vascularization and TAM Repolarization}

The high consumption of nutrients and oxygen by the cancer cell mass demands a constant and sufficient intratumoral blood flow. To that end, angiogenesis is promoted in the TME through excessive secretion of pro-angiogenic factors, such as vascular endothelial growth factors (VEGFs). However, this uncontrolled tumor vascularization leads to imperfect and leaky blood vessels, promoting metastatic dissemination and intratumoral hypoxia (70). For a long time, the preferred strategy was to further disrupt the vessel composition in order to starve cancer cells. However, this resulted in a more aggressive tumor and often increased metastatic outgrowth. These findings suggest that the opposite strategy, i.e., improving the functionality of the tumor vasculature (also termed vessel normalization), might be more beneficial to the patient (71). Both aforementioned strategies also have their impact on the TAM composition in the TME.

Although intratumoral vessel disruption strategies lead to more aggressive cancer progression and metastasis, their use has also been shown to elicit macrophage phenotype skewing, demonstrating potential tumor-suppressive functions. An example of this strategy is the vascular disrupting agent 5,6di-methylxanthenone-4-acetic acid, DMXAA, which was shown to induce the repolarization of M2-like TAMs to an M1-like phenotype in a mouse model of non-small cell lung cancer (72). However, vascular disruption also resulted in increased hypoxia, leading to the subsequent activation of HIF- $1 \alpha$, resulting in a more aggressive cancer phenotype. Accordingly, inhibition of HIF- $1 \alpha$ using digoxin was synergistic with DMXAA and led to stronger inhibition of tumor growth and metastasis of murine B16-F10 melanoma than DMXAA or digoxin alone (73). However, the direct effect of the treatment on M1-like TAMs remains to be elucidated. Another vascular disruption agent which showed such characteristics, is Z-GP-DAVLBH, which induced the secretion of GM-CSF and the skewing of M2-like to M1-like TAMs in hepatocellular carcinoma and breast cancer xenografts, leading to higher rates of cancer cell apoptosis (74).

Vessel normalization strategies, such as the inhibition of ANG2 and VEGF, also have the potential to induce repolarization of TAMs. In murine and human glioblastoma models, a bispecific antibody against ANG2/VEGF was shown to induce prolonged survival through reprogramming of TAMs from a 
M2 to a M1 phenotype (75). Similar observations were made by other research groups when using peptibodies inhibiting both the ANG2 and VEGF receptors or a bispecific antibody inhibiting ANG2 and VEGF themselves (76-78). Finally, another factor capable of promoting TAM repolarization and vessel normalization is histidine-rich glycoprotein (HRG), which is generally only expressed in low levels in the TME. A gain-offunction experiment, transducing HRG in T241 fibrosarcoma, Panc02 pancreatic carcinoma and 4T1 breast carcinoma models, showed reduced growth mediated by an increased presence of M1-like TAMs (79).

\section{Alternative Strategies Increasing M1/M2 Ratios}

The use of antibodies in the reprogramming of TAM ratios has also proven successful when agonistic anti-CD40 antibodies were administered in combination with gemcitabine, resulting in tumor regression in both mice and human patients with pancreatic ductal carcinoma (80). In this study, tumor regression did not seem to depend on gemcitabine or $\mathrm{T}$ cells, but on the presence of activated macrophages (80). Interestingly, CD40 agonist antibodies have been shown to induce tumoricidal properties in macrophages and to promote the maturation of antigen presenting cells, making them an ideal choice for combination therapies with immune checkpoint inhibitors $(81,82)$.

Similarly, antibody-mediated targeting of other surface receptors such as the pattern recognition receptor MARCO on TAMs resulted in altered macrophage polarization and a reduction in tumor growth and metastasis in a mouse model of breast cancer (83).

Moreover, the intratumoral localization of TAMs within the TME can also be targeted, as hypoxia or increased lactate levels, induces a proangiogenic, immunosuppressive TAM phenotype $(25,84)$. Therefore, retaining the TAMs in normoxic regions in order to prevent M2-like TAM differentiation could prove to be a valuable strategy. Blunting the Sema3A/Neuropilin-1 pathway through genetic deletion of neuropilin-1 in mice demonstrated decreased migration of TAMs to the hypoxic regions, resulting in a strengthened immune response (85).

A strategy which does not involve direct reprogramming of the macrophages, comprises the blockade of the "don't eat me" signal CD47, which is overexpressed by most cancer cells, or its corresponding receptor on macrophages, signal regulatory protein $\alpha(\operatorname{SIRP} \alpha) \cdot \operatorname{SIRP} \alpha$ interacts with $\operatorname{CD} 47$, leading to the downregulation of phagocytotic programs. Hence, inhibition of CD47 signaling increases phagocytosis by TAMs (86). These observations prompted clinical trials with anti-CD47 antibodies, which are currently ongoing (87). Alternatively, the administration of a CD47 antagonist, namely the engineered $\operatorname{SIRP} \alpha$ variant CV1, in combination with other molecules inducing phagocytosis, such as IgG4, significantly increased the phagocytic activity of macrophages and suppressed tumor growth of xenografts in mice (88).

In the search for molecules that could prolong survival of cancer patients, the anti-malaria drug chloroquine was tested. As a small molecule with a long clinical record which is affordable for clinical use, it was proven to induce repolarization of M2 macrophages toward the tumoricidal phenotype in the murine B16 melanoma model, showing promising results for future clinical trials (89). Another experimental treatment involved the use of a copper chelate to trigger activation of mitogenactivated protein (MAP) kinases via ROS generation. This led to the upregulation of IL-12 and IFN $\gamma$ production and subsequent repolarization of the tumor-promoting M2 TAMs in the Ehrlich ascites carcinoma model (90).

Overall, repolarization of TAMs appears to be a viable approach based on a large number of preclinical studies using a wide range of therapeutic agents, however, the safety and clinical efficacy of most therapies still remain to be investigated.

\section{DENDRITIC CELLS}

The bridge between the adaptive and the innate immune system is formed by antigen presenting cells (APC) such as dendritic cells (DCs). DCs are specialized in the processing of foreign antigens and their subsequent presentation, alongside relevant costimulatory molecules, to effector cells of the adaptive immune system in secondary lymphoid organs, such as the lymph nodes. Eventually, these effector cells, being cytotoxic $\mathrm{CD}^{+} \mathrm{T}$ cells, helper $\mathrm{CD}^{+}{ }^{+} \mathrm{T}$ cells and $\mathrm{B}$ cells, will differentiate and engage in the elimination of those cells expressing the foreign antigen.

\section{Identity}

DCs can be subdivided into two distinct specialized lineages, being the conventional/myeloid DCs (cDCs) and the plasmacytoid DCs (pDCs) (Figure 1). Both in mice and in humans, the existence of two $\mathrm{CDC}$ populations was demonstrated: $\mathrm{CD} 8 \alpha^{+}$or $\mathrm{CD}_{103}{ }^{+} \mathrm{cDC} 1 \mathrm{~s}$ and $\mathrm{CD} 11 \mathrm{~b}{ }^{+} \mathrm{cDC} 2 \mathrm{~s}$ in mice and $\mathrm{CD}_{141}{ }^{+}$(or $\mathrm{BDCA}^{+}$) $\mathrm{cDC} 1 \mathrm{~s}$ and $\mathrm{CD}_{1} \mathrm{c}^{+}$(or $\mathrm{BDCA1}^{+}$) $\mathrm{cDC} 2 \mathrm{~s}$ in humans (91-93). Finally, a population of monocyte-derived DCs (Mo-DCs) is also distinguished both in mice and in humans, as part of the myeloid DC lineage $(94,95)$. Based on single-cell RNA sequencing data, six populations were distinguished in human peripheral blood during steadystate. Two populations were identified as two $\mathrm{cDC} 2 \mathrm{CD}^{+} \mathrm{c}^{+}$ subpopulations and one was appointed as a new unidentified population of $\mathrm{AXL}^{+}$SIGLEC6 $^{+}$cells (95). The latter was shown to stimulate both $\mathrm{CD}^{+}$and $\mathrm{CD}^{+}$T-cell proliferation in a way similar to $\mathrm{cDCs}$, while they express several $\mathrm{pDC}$ markers as well. Other populations resembled the CLEC9A ${ }^{+} \mathrm{CDC1}$, the CD1c ${ }^{-} \mathrm{CD}_{141}{ }^{-} \mathrm{CD} 11 \mathrm{c}^{+}$monocyte-derived DCs (mo-DCs) and pDCs (95).

The cDC1s were shown to interact mainly with $\mathrm{CD}^{+} \mathrm{T}$ cells to induce potent CTL responses, while $\mathrm{cDC} 2 \mathrm{~s}$ can induce Th2 or Th17 responses, through presentation of tumor associated antigens (TAAs) on their MHC-II complexes (12, 94, 96). Plasmacytoid DCs engage in the secretion of type-I IFN, IL-6, and TNF- $\alpha$ and in this way interact with $\mathrm{cDCs}$, T cells and B cells in order to counteract infections (97). Mo-DCs arise from monocytes during inflammation, and could hence be seen as an activated type of macrophages, and have been shown to express immunosuppressive properties $(94,98)$.

Within the TME, DCs were originally described as immunosuppressive cells, characterized by an immature 
differentiation state, marked by a high antigen uptake and inadequate antigen presentation (99). These DCs are thought to enable further tumor growth and are therefore referred to as tolerogenic or regulatory DCs (9). The factors, responsible for the shift and maintenance of the immunosuppressive TADC phenotype are described in Conejo-Garcia et al. (100), while the mode of regulation by which these TADC exhibit immune suppression is reviewed in Keirsse et al. (9). Interestingly, the coexistence of distinct $\mathrm{cDC}$ subsets with anti-tumoral properties was recently shown in several murine models and patient biopsies $(94,101,102)$. In this review, we focus on the anti-tumoral properties of TADCs and the strategies deploying TADCs for immune therapy.

\section{Vaccination Strategies}

DCs display a high potential for the development of immunotherapy, considering their ability to induce a potent anti-tumoral immune response involving the activation of anti-tumoral $\mathrm{T}$ cells $\left(\mathrm{CD}^{+}\right.$and $\left.\mathrm{CD}^{+}\right)$. These anti-tumoral $\mathrm{T}$ cells are not only capable of fighting the primary tumor but also their metastatic lesions and potential recurrence. The development of DC-based immunotherapy led to the emergence of DC-based vaccines, whereby DCs are activated through: (i) ex vivo incubation with a maturation cocktail containing cytokines and/or TLR agonists, (ii) the administration of TAAs ex vivo or in vivo, or (iii) intra-tumoral administration of immuno-stimulatory molecules that activate TADCs. These DC-based vaccines can be categorized into distinct generations based on when they were first applied in the clinic (103), and are intensively studied in (pre-)clinical trials for their application in future cancer immunotherapy (104).

First generation DC-vaccines involved Mo-DCs that were isolated from the blood of the patient or that were generated ex vivo (105). However, these DCs were not matured any further using maturation cocktails, but were incubated ex vivo with synthetic TAAs or tumor lysates. The fact that these cells remained largely immature explains their inability to elicit a strong and durable anti-tumoral response (105). Therefore, during development of the second generation of DC vaccines, Mo-DCs were maturated using a maturation cocktail containing both cytokines and TAAs, successfully activating the APC properties of the dendritic cells (106). The first DCbased vaccination strategy that received FDA approval, being Sipuleucel-T in 2010, which specifically acts against metastatic castration-resistant prostate cancer (CRPC) is an example of a second-generation DC vaccines. In this strategy, immature dendritic cells were isolated from the blood and incubated with a fusion protein PA2024, which contains GM-CSF, a prostate antigen and prostate acid phosphatase (107).

The delivery of antigens to DCs can be performed in vivo or ex vivo through several strategies listed by Garg et al. (104). The genetic modification of dendritic cells for more efficient vaccine activity using mRNA and siRNA but also viral transfection and fusion with malignant cells has been reviewed in Abraham et al. The application of this approach is generally to improve cancer cell-targeting, however it also helps in reducing the effect of tumor-mediated immunosuppression on the reinjected DCs (108).

Recent developed strategies aim for the in vivo loading of TAAs, without the need for additional in vitro maturation or treatment. This involves the in vivo injection and targeting of TAAs to dendritic cells (109). However, recent research in mice demonstrated the potential of using TADCs ( $\mathrm{cDC} 1$ and $\mathrm{cDC} 2)$ isolated directly from the primary tumor (94). The reinjection of these TADCs, which took up the TAAs in vivo, led to the onset of immunological memory. Prophylactic vaccination with tumorderived $\mathrm{cDC1}$ s elicited an anti-tumor CTL response in B16OVA melanomas, whereas CDC2 vaccination reduced LLC-OVA tumor growth through a Th17 response (94). It remains to be elucidated, whether tumor-derived DCs can induce an efficient memory response against tumor antigens in cancer patients.

The antigen-loading can also be induced by immunogenic cell death (ICD), in which cancer cell apoptosis is induced, resulting in the release of antigens (110). As such, photodynamic therapy, which generates ROS-mediated ER stress, induced immunogenic apoptosis in cancer cells characterized by phenotypic maturation and functional stimulation of dendritic cells as well as induction of a protective antitumor immune response (111). This strategy has been shown to increase the survival of high grade glioma-bearing mice when activated DCs were administered as a prophylactic vaccine (110). In combination with conventional chemotherapy (temozolomide), the ICDbased DC vaccines enabled an increased survival and complete tumor rejection (110). Similarly, the treatment of cancer cells with high hydrostatic pressure enhanced the in vitro uptake and presentation of TAA. This DC-based vaccine inhibited tumor growth of TC1 tumors in mice when combined with docetaxel chemotherapy (112).

\section{Combining DC-Vaccination With Co-stimulatory Molecules}

Success rates of DC-based vaccination strategies can be improved through co-injections of stimulatory molecules, like TLR agonists or CD40 agonists, which can enhance the antigen presenting function of TADCs (109). In vivo TAA presentation by TADCs can be induced through the intratumoral injection of TriMix mRNA, containing mRNA coding for the CD70 costimulatory molecule, the activation stimulus CD40L, and constitutively active TLR4 (113). Administration of DCs electroporated with TriMix mRNA and a melanoma antigen (gp100, tyrosinase, MAGE-A3 or MAGE-C2 fused to DC.LAMP) demonstrated durable clinical benefit in clinical trials involving patients with advanced melanoma when combined with the CTLA-4 inhibitor ipilimumab $(114,115)$. CD40 signaling induces important changes in DCs, including the induction of antigen presentation and upregulation of MHC- II and costimulatory molecules CD80 and CD86 (116). The use of an agonistic anti-CD40 antibody proved to successfully activate cDC populations (117), making it an interesting adjuvant for DC vaccination. Moreover, CD40 and TLR agonists act synergistically and the combination of these immunostimulants can significantly suppress B16-F10 tumor growth in mice 
(118). Aside from CD40L, Fms-like tyrosine kinase 3 receptor ligand (Flt3L), a potent growth factor typically associated with DC development (119), was also suggested as an interesting candidate for the maturation of the TADCs. In this respect, coadministration of an adenoviral vector encoding Flt3L (pAdFlt3L) and cell lysate of the colon cancer model CT26 into the footpad of the mouse prior to subcutaneous injection at the same location with CT26 resulted in the successful priming of both $\mathrm{cDCs}$ and $\mathrm{pDCs}$, enabling tumor regression (120).

Other promising candidates are the TLR7/8 agonist FSME, which stimulates pDCs, and GM-CSF, which promotes myeloidderived DC maturation. Administration of FSME or GM-CSF prior to DC vaccination in melanoma patients resulted in the induction of potent anti-tumor immune responses $(121,122)$. Also, intratumoral injection of GM-CSF secreting whole cell tumor cell vector (GVAX) formulated with the TLR4 agonist LPS showed potent induction of DC maturation and therapeutic efficacy in CDT26-tumor bearing mice (123).

Interestingly, Salmon et al. observed significant activation of $\mathrm{CD}_{103}{ }^{+} \mathrm{DC}$ progenitors (cDC1s) in the TME of the B16-OVA breast cancer model in mice after systemic administration of Flt3L, alongside intratumoral injection of the TLR3 agonist poly I:C (124). This therapy also enhanced the response to anti-PD-L1 therapy and BRAF inhibition (124), opening up possibilities for combination therapy with both immune checkpoint inhibitors and DC vaccination. The TLR3 agonist poly I:C was also employed in the development of a nanovaccine which was loaded with poly I:C, together with small interfering RNA (siRNA) against STAT3 and the ovalbumin antigen. The use of this carrier induced a significant tumor regression of B16-OVA tumors in mice with an increase of TADCs and decrease of immunosuppressive cells in the tumor draining lymph nodes (125). Similarly, a poly(lactic-co-glycolic acid) nanoparticle loaded with poly I:C and coated with a CD40 agonist antibody was directed toward CD40 expressing

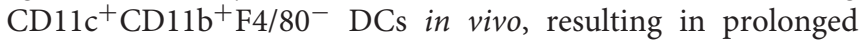
survival of B16-OVA-tumor bearing mice (126). While the use of nanocarriers, which facilitate the in vivo delivery of antigens to dendritic cells, represents a promising strategy, it still requires validation through clinical trials in human patients.

The immune system in cancer patients is not only suppressed in the TME, but is altered systemically, whereby activation of immune cells in the draining lymph nodes is also counteracted (127). Intradermal injection of combined CpG-B/GM-CSF administration resulted in enhanced in vivo maturation and frequencies of $\mathrm{cDCs}$ in the lymph nodes of patients with stage I-II melanoma and these cDCs displayed increased crosspresentation capacities after ex vivo culture (128), suggesting the potential of CpG-B/GM-CSF as a possible new combination partner for DC-based immunotherapies against metastatic spread. Given the existence of systemic immune suppression, tumor-specific $\mathrm{CD}^{+}$T-cell responses mediated by DCvaccinations can be maximized using a multi-site injection strategy. This approach has been applied using a replicationdeficient adenovirus serotype 5 -vectored cancer vaccine. This vaccine specifically targeted the dopachrome tautomerase antigen in melanoma and led to an increase in systemic TAAspecific T-cells. Hence, the use of multi-site injections could also show potential in future DC vaccination strategies (129). Since systemic activation of the immune system in cancer is considered as beneficial for the efficacy of immunotherapy (130), systemic activation of DCs leading to an anti-tumoral immune response is another field of investigation. With the administration of RNA-lipoplexes, lipid carriers containing RNA encoding antigens (ovalbumin, gp70), efficient systemic uptake by DCs led to maturation and induction of effector/memory $\mathrm{T}$-cell responses resulting in IFN $\alpha$-mediated tumor inhibition (131).

\section{Other DC-Based Strategies}

The amount of $\mathrm{cDCs}$ that can be recovered from the circulation or tumors can be critical for enabling DC-based vaccination strategies. The accumulation of $\mathrm{cDC} 1 \mathrm{~s}$ appears to depend, besides Flt3L signaling, also on natural killer $(\mathrm{NK})$ cells that secrete CCL5 and XCL1, which are potent CDC1 chemoattractants. Böttcher et al. proved in mice that the production of $\mathrm{PGE}_{2}$ by the tumor impaired $\mathrm{NK}$ cell chemokine secretion and cDC1 chemokine receptor expression, leading to a decreased recruitment and anti-tumoral action of $\mathrm{CDC1s}$ in the tumor (132). The discovery of the CCL5-XCL1 mediated attraction of $\mathrm{cDC} 1 \mathrm{~s}$ into the TME, opens possibilities for future cancer immunotherapy, employing injection of these chemokines intratumorally alongside intranodal injection of TAA-loaded cDC1s. Efficient cross-presentation of tumor antigens to $\mathrm{CD}^{+}$ $\mathrm{T}$ cells by $\mathrm{cDC} 1 \mathrm{~s}$ is a major determinant of antitumor immune responses, thus therapeutic enhancement of this activity in the TME and the lymph nodes is of great interest (133).

A recent strategy shown to induce a cytotoxic T-cell response and NK cell activation, comprises the use of DC-derived exosomes, which contain functional MHC complexes (both MHC-I and-II) including costimulatory molecules (134) and demonstrated to successfully slow down tumor growth and increase a anti-tumoral immune cell infiltration when injected intravenously in a murine hepatocellular carcinoma model (135).

Lastly, low-dose administration of chemotherapeutic agents such as cyclophosphamide or paclitaxel was shown to enhance DC maturation, migration and function (136). Administration of immature DCs in the peritumoral environment of head and neck cancer patients together with low-dose cyclophosphamide and docetaxel as well as a multi-cytokine inducer OK-432, reduced immunosuppression and enhanced T-cell immunity, as a consequence of DC maturation (137). Combination therapy with low-dose cyclophosphamide and DC vaccination also demonstrated to reduce the tumor-induced immune suppression in patients with mesothelioma (138).

\section{NEUTROPHILS}

Neutrophils are highly phagocytic innate immune cells that make up $50-70 \%$ of all circulating leukocytes and live 5 to $8 \mathrm{~h}$ in the blood (139). In the steady-state, neutrophils are retained 
in the bone marrow through the secretion of CXCL12 by osteoblasts. Upon infection and tissue damage, endothelial cells secrete CXCL1 and CXCL2, the major chemokines involved in the recruitment of the neutrophils, which are both recognized by CXCR2 (140). Another important player, counteracting retention of the neutrophils in the bone marrow is G-CSF (141). This growth factor does not only play an important role in the activation of neutrophils, but is also a major actor in the infiltration of neutrophils into the TME (142). When neutrophils migrate to the site of threat, they become activated and recruit other types of immune cells, leading to acute inflammation. When encountering harmful microorganisms, neutrophils will engage in three ways: (1) phagocytosis, (2) degranulation, and (3) release of neutrophil extracellular traps (NETs) (3).

Being the largest group of circulating white blood cells in the body, neutrophils play a substantial role in the interaction with malignant cell growth. Neutrophils in the TME, also called tumor associated neutrophils (TANs), tend to live longer (up to $17 \mathrm{~h}$ ) under the influence of different signals present in the tumor, such as G-CSF and hypoxia (143). In humans, neutrophils are identified through their expression of the cell surface markers CD66b, CD15, CD16, and CD10 (144). Additionally, the lectin-type oxidized low-density lipoprotein receptor-1 (LOX1) is a potent marker which can be used to separate them from polymorphonuclear-MDSCs (PMN-MDSCs) (145), which can be described as immature neutrophils and are $\mathrm{LOX}^{+}$(see section Myeloid-Derived Suppressor Cells). Besides these surface markers, it is also possible to identify TANs based on high expression of typical neutrophil-associated enzymes such as the serine protease neutrophil elastase (NE) (146) and myeloperoxidase (MPO) (147).

Peripheral blood neutrophil to lymphocyte ratio can be used in a clinical context as a prognostic biomarker and is associated with a poor overall survival in many solid tumors (148-150). TAN infiltration is mediated via the known neutrophil recruiting chemokines, being CXCL1, CXCL2, and CXCL5, secreted by cancer cells (Figure 1) (139, 151). Strikingly, it has also been shown that some malignancies can stimulate osteoblasts to upregulate the production and recruitment of tumor-promoting neutrophils (152). When neutrophils are initially recruited to the tumor, they appear to exhibit anti-tumoral properties and only over time become tumor-promoting, through the action of several factors secreted in the TME $(147,153)$. The initial tumor killing capacity of neutrophils is illustrated by an in vitro study, where Yan et al. demonstrated that neutrophils derived from the peripheral blood of healthy individuals were able to kill four different human cancer cell lines (154). Neutrophils, whose phenotype has switched toward tumor promotion facilitate metastasis (155), angiogenesis via secretion of proangiogenic factors, such as MMP9 and VEGF (156, 157) and immunosuppression either directly or through the recruitment of regulatory T cells (Tregs) (153).

\section{TAN Repolarization}

The tumor-suppressive properties of TANs appear to be reversible, based on mouse studies, leading to an anti-tumor neutrophil phenotype often termed $\mathrm{N} 1$ as opposed to the pro-tumor $\mathrm{N} 2$ phenotype, analogous to the M1/M2 concept used to describe the extremes of macrophage polarization. One of the central signals in the TME that induces the protumor TAN phenotype appears to be TGF $\beta$, which induces the expression of CXCL1, VEGF, and MMP9, which are all factors leading to a more persistent tumor growth (158). Accordingly, using a TGF $\beta$ receptor inhibitor SM16 led to a suppression of tumor growth by the anti-tumor N1like TANs in mice, which expressed TNF $\alpha, M I P 1 \alpha, \mathrm{H}_{2} \mathrm{O}_{2}$, and NO, ultimately being cytotoxic to cancer cells (159). Other molecules, such as type I IFNs can also induce the shift toward an anti-tumor TAN phenotype $(157,160,161)$. Therefore, it might be interesting to further explore the generation of N1-like TANs as a potential new immunotherapy approach.

\section{Increasing Anti-tumoral TAN Infiltration}

The creation of an acute inflammatory response instead of the wound-healing and tissue-repair response characteristic for the TME (162), could also prove to be a promising strategy. The ample evidence pointing toward the potential of neutrophils to serve as anti-tumor effectors was reviewed by Souto et al. (163). One of the approaches to enhance anti-tumor neutrophil infiltration could be radiotherapy. Infiltration of neutrophils producing large amounts of reactive oxygen species following radiotherapy were reported to exhibit a potent antitumor effect by inducing oxidative damage and apoptosis in cancer cells in several mouse tumor models (142). Therapies aiming to induce systemic neutrophil expansion (e.g., G$\mathrm{CSF}$ ) in combination with agents that promote the generation of anti-tumor neutrophils (e.g., TGF $\beta$ targeting) might act synergistically, and induce greater cytotoxicity in the tumor. It remains to be investigated, whether such combination therapies could be beneficial considering the largely negative effect of GCSF administration on disease outcome. Until now, G-CSF has been administered to induce neutrophil expansion in order to help patients recover from chemotherapy-induced neutropenia (141). However, many studies have shown negative effects of this growth factor on disease outcome $(141,164,165)$ and suggest G-CSF neutralization as a target for immunotherapy $(166,167)$. Accordingly, although administration of G-CSF in mice expanded neutrophils, it failed to induce a cytotoxic neutrophil response (168). Furthermore, in mice, G-CSF has also been shown to inhibit neutrophil migration through inhibition of CXCR2 (169). Therefore, other signaling molecules, such as intratumoral delivery of IL-8 could be used to stimulate neutrophil infiltration in order to induce acute inflammation and consequential inhibition of tumor growth (170, 171). A wide range of chemokines haven been shown to induce neutrophil cytotoxicity in vitro, including CCL2, CCL3, CCL5, CXCL1, CXCL12, and CXCL16, therefore approaches that increase the secretion of these factors in the TME might also prove to be beneficial (168). Inhibition of certain receptor tyrosine kinases (cMET, VEGFR2, RET, KIT, AXl, and FLT3) using a promiscuous small molecule inhibitor, cabozantinib, has also led to higher neutrophil infiltration into the tumor. Ultimately, 
these neutrophils induced a highly effective eradication of murine prostate cancer (172). The precise mechanism behind the higher infiltration is not entirely clear, as (1) the exact RTK targeted is not yet identified (172) and (2) the application of cabozantinib inhibited tumor infiltration of immature neutrophils in another study on a more aggressive type of prostate cancer (173).

\section{Inhibiting Immunosuppressive TAN Infiltration}

In contrast to inducing an acute form of inflammation via an increased neutrophil infiltration, in the last decade, many researchers have focused on developing strategies to inhibit neutrophil recruitment to the TME. This is due to the finding that neutrophils often acquire an immunosuppressive phenotype upon infiltration of the TME. One strategy in preclinical studies was the inhibition of the general neutrophil recruitment pathway, involving the blockade of the IL-8/CXCR1/CXCR2 axis (140) with CXCR2 antagonists (174) or anti-IL8 antibodies (156). Moreover, there are indications in mice that the inhibition of RTK MET can also result in decreased tumor infiltration of immunosuppressive neutrophils in response to adoptive T-cell therapy leading to enhanced anti-tumoral T-cell function (175). However, in certain murine tumor types, inhibition of MET has been reported to diminish infiltration of antitumor neutrophils, resulting in increased tumor growth and metastasis (176).

Another possible strategy could be the induction of reverse migration or retrotaxis of TANs out of the TME in the bloodstream, lowering the abundance of TANs in the tumor microenvironment. These reverse migrated TANs could then possibly induce a more systemic anti-tumor response by antigen presentation or direct T-cell stimulation (177, 178). Therapeutic induction of neutrophil reverse migration has only been witnessed in case of wound-induced inflammation, however the development of reverse migration-inducing drugs might potentially open up opportunities for future cancer therapies (179). Two signaling pathways involved in reverse migration have already been discovered, namely the redox-regulated Src family kinase signaling (180) and the leukotriene B4-neutrophil elastase axis (181).

\section{Other TAN-Based Strategies}

Other strategies that have been investigated to target neutrophils in the TME involve inhibition of enzymes and mediators known to induce pro-tumorigenic properties, namely NE (182), a2 isoform V-ATPase (146), arachidonate 5-lipoxygenase (155), IL23 (139), and IL-17 (183). Again, the latter can also promote antitumor activities (158), illustrating that the role of TANs appears to be highly context-dependent, determined by the histological origin and stage of the tumor as well as the therapies applied in the treatment.

\section{MYELOID-DERIVED SUPPRESSOR CELLS}

Myeloid-derived suppressor cells (MDSCs) comprise a heterogeneous group of immature myeloid cells characterized by their co-expression of CD11b and GR1 (184). In mice, two large populations can be distinguished, called polymorphonuclear
(PMN)-MDSCs and monocytic (MO)-MDSCs (Figure 1).

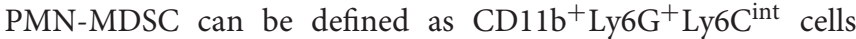
with high production of ROS, while MO-MDSC on the other hand are defined as $\mathrm{CD} 11 \mathrm{~b}^{+} \mathrm{Ly}_{6 \mathrm{G}}^{-} \mathrm{Ly} 6 \mathrm{C}^{\text {high }}$ cells with high NO production $(185,186)$. In humans, MDSCs comprise three populations, a PMN-MDSC population identified by a $\mathrm{CD} 14^{-} \mathrm{CD} 11 \mathrm{~b}^{+} \mathrm{CD}_{15}{ }^{+}$(or $\mathrm{CD}^{+} 6^{+}$) profile, a MO-MDSC population defined by a $\mathrm{CD} 14^{+} \mathrm{CD} 11 \mathrm{~b}^{+} \mathrm{HLA}-\mathrm{DR} \mathrm{low}^{\text {low }} \mathrm{CD} 15^{-}$ phenotype and a population of "early stage MDSCs" or eMDSCs identified through the HLA-DR ${ }^{-} / \mathrm{CD} 33^{+} \mathrm{Lin}^{-}$profile (with Lin being CD3/14/15/19/56) (184). The presence of MDSCs is not restricted to cancer, but can occur in every form of chronic inflammation, including pathogenic infection (187), autoimmune diseases (188), and Alzheimer's disease (189). Their main role during inflammation is to temper the immune response in order to protect the body from tissue damage that can be caused by a prolonged and uncontrolled immune response $(6,190)$.

Tumor-associated MDSCs arise in the TME as the result of two groups of overlapping signals. On one hand, the presence of factors, such as GM-CSF, G-CSF, and M-CSF causes expansion of immature myeloid cells. On the other hand, a wide range of pro-inflammatory factors, e.g., PGE 2 , TNF, IL-1 $\beta$, IL-6, S100A8, S100A9, IFN $\gamma$, IL-4, IL-10, and IL-13 secreted by cancer cells and leukocytes residing in the tumor inhibit the differentiation of myeloid progenitors and enhance their suppressive capacity (191). During cancer progression, MDSC levels do not only rise in the TME, but also increase in the spleen (192) and bone marrow (193), where they exert inhibitory functions on the immune system. However, the MDSCs in the TME were shown to exhibit higher immunosuppressive capacities than the peripheral MDSCs from the spleen (194) or bone marrow (193). In the TME of most cancer types, the PMNMDSC fraction makes up around $80 \%$ of the total MDSC (6), with most of the MO-MDSC rapidly differentiating into TAMs (47).

In the TME, MDSCs exhibit different tumor-promoting and immunosuppressive functions and hence correlate with poor prognosis in cancer patients (195). The tumor-promoting functions comprise (i) remodeling of the TME (196), (ii) induction of (lymph)angiogenesis (196), (iii) promotion of metastasis (197), (iv) inhibition of cellular senescence (198), (v) suppression of T-cell function and migration (199, 200) and (vi) resistance to chemo-and immunotherapy (201-203). It is important to note that the immunosuppressive activity of MDSCs is not limited to a single mechanism, with MDSCs engaging several mechanisms throughout the progression of the tumor (6, 204-206), including; (i) expansion of Tregs (207), (ii) expression of galectin-9 on the MDSC surface, resulting in T-cell apoptosis (208), (iii) inhibition of NK cells through membranebound TGF $\beta 1$ (209), (iv) the secretion of ROS $\left[\mathrm{O}_{2}^{-}, \mathrm{H}_{2} \mathrm{O}_{2}\right.$ and peroxynitrite $\left.\left(\mathrm{OONO}^{-}\right)\right](210,211)$, (v) expression of enzymes involved in amino acid catabolism, like Arginase-I and IDO, collectively inhibiting T-cell proliferation (212, 213), and (vi) secretion of S100A8 and S100A9, resulting in the recruitment of more MDSCs and inhibition of dendritic cell maturation $(214,215)$. 
Treatments targeting MDSCs in the TME aim to (i) reduce the number of MDSCs via their elimination or inhibition of recruitment or (ii) induce "re-education" or differentiation of these cells into anti-tumoral cells.

\section{Elimination of MDSCs or Inhibition of MDSC Recruitment}

In order to counteract the immunosuppressive actions of MDSCs, many depletion strategies have been applied (Table 1). The use of the chemotherapeutic agents gemcitabine, 5fluorouracil and cisplatin, is able to eliminate MDSCs in murine tumors by inducing their apoptosis (216-218). As mentioned above, S100A9 is one of the central inflammatory mediators promoting MDSC recruitment. Accordingly, peptibodies against S100A9 led to reduced MDSC recruitment in tumor-bearing mice (219). Tyrosine kinase inhibitors, such as ibrutinib and sunitinib, respectively in mice and in humans, have also been shown to decrease tumor growth and decrease the numbers of MDSCs present in the TME (221, 225). Interestingly, the antidiabetic drug phenformin has been recently shown to selectively deplete PMN-MDSCs in the TME in mouse models of melanoma through the activation of AMPK (226). Activation of TRAIL receptor 2 (TRAIL-R2, also known as DR5) using an agonist antibody provides a more selective approach to induce MDSC apoptosis due to high expression of TRAIL-R2 on MDSCs (231). The TRAIL-R2-targeting antibody has already progressed to a phase I clinical trial, which demonstrated efficient depletion of MDSCs (particularly PMN-MDSCs) in the blood of patients with various solid tumor types (224). Interestingly, however, only a subset of patients showed a decrease of MDSCs in the tumor microenvironment (224).

Since both MO-MDCSs and TAMs derive from monocytic precursors, many inhibitors described to reduce the abundance of TAMs (cfr partim Macrophages) can be used to inhibit MOMDSC recruitment as well (Table 1). For instance, in mice the use of the CSF-1R inhibitors GW2850 and PLX3397, led to a reduced recruitment of MO-MDSCs in the TME (227). Aside from CSF-1R inhibitors, the inhibition of $\mathrm{PI}_{3} \mathrm{~K} \gamma$ or integrin $\alpha_{4}$ prevented the accumulation of MDSCs as well as the expression of immunosuppressive molecules in the TME of LLC tumors (223). Analogously, genetic deletion of integrin- $\alpha \mathrm{M}$ (also known as CD11b) in mice resulted in decreased recruitment of PMN-MDSCs to colorectal carcinomas and led to reduced tumor burden and improved survival, establishing integrin$\alpha \mathrm{M}$ as an additional therapeutic target (228). Similar findings were observed after inhibition of the IL-6/STAT3 pathways, leading to a significant inhibition of MDSC expansion and tumor growth of the murine TC1 tumor model (222). Also in mice, SAR131675, an inhibitor of VEGFR-3, led to a reduction in the frequency of MDSCs in the tumor and in the spleen (220). In patients, the inhibition of phosphodiesterase 5 using tadalafil reduced peripheral MDSC numbers which was associated with an enhanced proliferative capacity of patient-derived $\mathrm{T}$ cells in head and neck squamous cell carcinoma (230). Epigenetic modulators are generally thought to primarily affect cancer cells through inducing reexpression of silenced genes often involved in antigen presentation, potentially leading to enhanced antitumor immunity. However, administration of 5-azacytidine and entinostat to inhibit DNA methyltransferases and class I HDAC enzymes, respectively, has been shown reduce circulating and tumor-infiltrating PMN-MDSC levels which led to improved responses to immune checkpoint blockade therapy in mice (229). Interestingly, entinostat but not 5-azacytidine markedly reduced the viability of MDSCs (229). Nevertheless, the exact mechanism by which epigenetic regulators exert their inhibitory function on MDSCs remains to be elucidated.

The interplay of MDSCs with mast cells has also been considered an interesting future target. While mast cells have been associated with allergic reactions, they have also been reported to play either an immunostimulatory or an immunosuppressive role in the TME, depending on the tumor type (232). In the tumor-promoting context, mast cells do not only secrete immunosuppressive cytokines, but are also involved in the recruitment of MDSCs (233). Therefore, targeting the recruitment/function of tumor infiltrating mast cells could lead to diminished recruitment of MDSCs to the TME. Only few depletion strategies have been employed, which are reviewed in Varricchi et al. (232). Hence, further research on mast cells as a potential target in cancer immunotherapy is still needed.

Although the inhibition of MDSC recruitment to the TME provides a promising strategy, it can also be of interest to promote the differentiation of MDSCs toward either mature myeloid cells with antigen-presenting and/or cytotoxic activity.

\section{Differentiation of MDSCs Into Anti-tumoral Myeloid Cells}

A method to convert immunosuppressive MDSC to anti-tumoral myeloid cells might rely on TLR activation. For instance, the administration of a TLR7/8 agonist, resiquimod, led to the differentiation of bone marrow-derived MO-MDSC into F4/80 macrophages and $\mathrm{CD} 11 \mathrm{c}^{+}$dendritic cells in vitro $(234,235)$. A recent study by Shayan et al. also demonstrated that the use of a TLR8 agonist in combination with the EGFR inhibitor cetuximab led to repolarization of monocytes toward an M1-like TAM phenotype and resulted in less MDSC-mediated suppression of T-cell activity in vitro. Furthermore, administration of the combination treatment was associated with a more immunepermissive TME in patients with head and neck squamous cell carcinoma (236). This however raises the question whether the differentiated monocytes were in fact MO-MDSCs that differentiated toward an anti-tumoral M1 TAM, as proposed in Wang et al. [2015] or whether the differentiation of monocytes toward M1-like TAMs overruled the suppressive actions of the MDSCs present in the TME (237).

Conversely, TLRs can also be involved in sustaining MDSCmediated immune suppression. For instance, in pancreatic cancer in mice, TLR9 activation has been shown to induce MDSC proliferation in vivo and activate pancreatic stellate cells to display protumorigenic effects in vitro (238). Accordingly, activating TLR2 signaling in the murine EG7 lymphoma model via the Pam2CSK4 lipopeptide, leads to an increased immunosuppressive activity of MO-MDSCs as they further 
TABLE 1 | Myeloid-derived suppressor cell depletion or recruitment inhibition strategies in murine cancer models and patients.

\begin{tabular}{|c|c|c|c|c|c|}
\hline Tumor model & Treatment & Target & Amount/type of MDSC & Outcome & Reference \\
\hline $\begin{array}{l}\text { Mouse } \\
\text { Lymphoma/melanoma }\end{array}$ & $\begin{array}{l}\text { Gemcitabine-loaded } \\
\text { nanopatricles }\end{array}$ & DNA synthesis & MO-MDSCs depletion & Attenuated immune suppression & (216) \\
\hline $\begin{array}{l}\text { Mouse } \\
\text { Melanoma }\end{array}$ & Cisplatin & DNA-synthesis & MDSCs depletion & $\begin{array}{l}\text { Partially abrogated immune } \\
\text { suppression }\end{array}$ & (218) \\
\hline $\begin{array}{l}\text { Mouse } \\
\text { Thymoma }\end{array}$ & $\begin{array}{l}\text { Pep-H6 } \\
\text { Pep-G3 }\end{array}$ & S100A9 & MDSC depletion & Retardation tumor growth & (219) \\
\hline $\begin{array}{l}\text { Mouse } \\
\text { Breast carcinoma }\end{array}$ & SAR131675 & VEGFR & $\begin{array}{l}\text { Prevents MDSC } \\
\text { accumulation + } \\
\text { M1-like TAM differentiation }\end{array}$ & $\begin{array}{l}\text { Reduced tumor growth and } \\
\text { metastasis }\end{array}$ & (220) \\
\hline $\begin{array}{l}\text { Mouse } \\
\text { Melanoma }\end{array}$ & Ibrutinib & Bruton's tyrosine kinase & MDSC reduced & $\begin{array}{l}\text { Enhanced the efficacy of } \\
\text { anti-PD-L1 }\end{array}$ & (221) \\
\hline $\begin{array}{l}\text { Mouse } \\
\text { HPV-expressing TC-1 cells }\end{array}$ & Anti-IL6R mAb & IL6 & MDSC reduced & Reduced tumor growth & (222) \\
\hline $\begin{array}{l}\text { Mouse } \\
\text { Melanoma }\end{array}$ & Phenformin (+anti-PD1) & $\begin{array}{l}\text { Mitochondrial complex } 1 \text { of } \\
\text { the respiratory chain }(+ \\
\text { PD1) }\end{array}$ & $\begin{array}{l}\text { PMN-MDSC depletion in } \\
\text { spleen }\end{array}$ & Reduced tumor growth & (226) \\
\hline $\begin{array}{l}\text { Mouse } \\
\text { Sarcoma }\end{array}$ & $\begin{array}{l}\text { GW2850 } \\
\text { PLX3397 }\end{array}$ & CSF1R & $\begin{array}{l}\text { Prevents MO-MDSC } \\
\text { accumulation }\end{array}$ & Reduced tumor growth & (227) \\
\hline $\begin{array}{l}\text { Mouse } \\
\text { Colorectal carcinoma }\end{array}$ & CD11b KO & CD11b & $\begin{array}{l}\text { Decreased } \\
\text { MDSC accumulation }\end{array}$ & Reduced tumor growth & (228) \\
\hline $\begin{array}{l}\text { Mouse } \\
\text { Breast carcinoma } \\
\text { Colon carcinoma }\end{array}$ & $\begin{array}{l}\text { Entinostat } \\
\text { (+ anti-PDL1 } \\
+ \text { anti-CTLA4) }\end{array}$ & Class I HDAC & MDSC inhibition & Reduced tumor growth & (229) \\
\hline
\end{tabular}

differentiate into protumoral macrophages (239). However, the administration of N6-(1-Iminoethyl)-L-lysine (L-NIL), an iNOS inhibitor, decreased the immunosuppressive effect, showing the therapeutic potential of Pam2CSK4 when used in combination with other therapeutic agents (239). Another ligand for TLR2, Hsp72, has also proven to activate and increase the suppressive capacities of MDSCs in murine lymphoma, mammary carcinoma and colon carcinoma models, and showed relevance in humans as the human tumor cell line TDE triggered the suppressive function of MDSCs in a Hsp72 dependent manner (240). Also Hsp90, a regulator of TLR4 signaling, showed to be involved in the induction of the suppressive capacities of MDSCs in vitro (241). Therefore, the use of TLRs in MDSC-based immunotherapy remains to be further investigated.

Interestingly, oral administration of yeast-derived whole $\beta$ glucan particles (WGP) activated the dectin-1 receptor, leading to reduced amounts of PMN-MDSC in the spleens and tumors of LLC and E0771 tumor-bearing mice and decreased their immunosuppressive properties in vitro. In an in vitro assay, the presence of WGP induced the differentiation of MO-MDSC into $\mathrm{F} 4 / 80^{+} \mathrm{CD} 11 \mathrm{c}^{+}$myeloid cells, serving as potent APCs and when injected intratumorally, WGP-treated MO-MDSCs were capable of inhibiting tumor growth in subcutaneously inoculated LLC (242).

Using the antibody $2 \mathrm{aG} 4$ against another therapeutic target, phosphatidylserine, also showed repolarization from M2-like TAMs to the M1-like phenotype, together with differentiation of MO-MDSCs into M1-like TAMs and dendritic cells in vitro (243). Interestingly, curcumin-based chemotherapy (docetaxel) showed to selectively eliminate the PMN-MDSCs, while sparing the MOMDSC which then repolarized toward M1-like TAMs in a murine 4T1 mammary carcinoma model (244).

A study performed on in vitro generated MDSCs co-cultured with the human A375 melanoma cell line demonstrated a shift of the MDSC phenotype toward a profile associated with immunostimulatory dendritic cells, through the inhibition of macrophage migration inhibitory factor (MIF) with 4-iodo6-phenylpyrimidine (245). However, these results remain to 
be confirmed in vivo before MIF inhibition can be further explored in a therapeutic setting. Shen et al. also witnessed a similar shift of the immunosuppressive MDSCs toward a more immunostimulatory myeloid cell type in response to tasquinimod, a quinoline-3-carboxyamide analog with antiangiogenic properties when administered to mice injected with either castration-resistant prostate cancer or melanoma cells (246).

Moreover, the administration of axitinib, a small molecule tyrosine kinase inhibitor of VEGFR-1/2/3, reduced the immunosuppressive activity of splenic and tumor-infiltrating MO-MDSCs besides its anti-angiogenic effect. Moreover, MO-MDSCs from axitinib-treated tumors in mice were able to stimulate T-cell activation, suggesting a phenotype switch from immunosuppressive to antigen-presenting activity (247).

\section{CONCLUDING REMARKS}

The use of tumor-associated immune cells unlocks an interesting field of potential therapies in the fight against cancer. Severe side effects inflicted by conventional therapies are overcome as the body's own immune system engages in specific anti-tumoral immune responses. Moreover, the genomic stability of tumorassociated immune cells as opposed to the high genetic plasticity and heterogeneity of cancer cells, decreases the risk of developing resistance against immunotherapies.

Still many hurdles are to be overcome in order to completely rely on the immune system to ensure specific and longterm immune responses against tumors. The observation that the abundance of myeloid cell (sub)population can differ substantially between tumor types $(248,249)$, urges for the verification of their therapeutic potential in distinct tumor models. Additionally, high variability in the frequency of distinct myeloid cell subsets is also witnessed between patients with the same tumor type (30-32). As highlighted in this review, clinical translation of some of the therapeutic strategies

\section{REFERENCES}

1. Hanahan D, Weinberg RA. Hallmarks of cancer: the next generation. Cell (2011) 144:646-74. doi: 10.1016/j.cell.2011.02.013

2. Mendes F, Domingues C, Rodrigues-Santos P, Abrantes AM, Gonçalves AC, Estrela J, et al. The role of immune system exhaustion on cancer cell escape and anti-tumor immune induction after irradiation. Biochim Biophys Acta Rev Cancer (2016) 1865:168-75. doi: 10.1016/j.bbcan.2016.02.002

3. Amulic B, Cazalet C, Hayes GL, Metzler KD, Zychlinsky A. Neutrophil function: from mechanisms to disease. Annu Rev Immunol. (2012) 30:45989. doi: 10.1146/annurev-immunol-020711-074942

4. De Vlaeminck Y, González-Rascón A, Goyvaerts C, Breckpot K. Cancerassociated myeloid regulatory cells. Front Immunol. (2016) 7:113. doi: 10.3389/fimmu.2016.00113

5. Steinberg SM, Shabaneh TB, Zhang P, Martyanov V, Li Z, Malik BT, et al. Myeloid cells that impair immunotherapy are restored in melanomas with acquired resistance to BRAF inhibitors. Cancer Res. (2017) 77:1599-610. doi: 10.1158/0008-5472.CAN-16-1755

6. Gabrilovich DI. Myeloid-derived suppressor cells. Cancer Immunol Res. (2017) 5:3-8. doi: 10.1158/2326-6066.CIR-16-0297

7. Poh AR, Ernst M. Targeting macrophages in cancer: from bench to bedside. Front Oncol. (2018) 8:1-16. doi: 10.3389/fonc.2018.00049 targeting myeloid cells is ongoing. The observations above have two crucial implications for future translational efforts. Firstly, murine models will likely fail to predict therapeutic responses to myeloid cell-based therapies in patients with cancer, as tumor models in mice, particularly transplantable ones, show rapid progression and low variability in their immune microenvironment. Thus, there is an urgent need for the development and application of more advanced pre-clinical models that recapitulate the patient-to-patient heterogeneity of the tumor immune microenvironment. Secondly, similar to ICIs, likely not all patients will benefit from myeloid cell-targeted therapies. Thus, it will be essential to investigate the differences between the responder and non-responder populations in order to identify biomarkers predicting therapy response. Due to the highly patient-specific nature of tumor antigens and the tumor immune microenvironment, the future myeloid-cell targeted therapies will have to be integrated in combination therapies tailored to each patient, in which adoptive T-cell transfer, ICIs, co-stimulatory molecules, low-dose chemo-or radiotherapy are combined with the (re)activation of tumor-associated myeloid cells.

\section{AUTHOR CONTRIBUTIONS}

EC wrote the manuscript draft. AM designed the figures $\mathrm{HV}$ revised the manuscript draft. MK and DL supervised and wrote the final manuscript with input from all authors.

\section{ACKNOWLEDGMENTS}

The authors apologize to those researchers whose work could not be cited. We thank Xenia Geeraerts and Evangelia Bolli for discussions on this topic. AM, HV, and MK are supported by $\mathrm{PhD}$ grants from the Research Foundation Flanders (FWO). DL is supported by grants from Kom op tegen kanker and Vrije Universiteit Brussel.
8. De Palma M, Lewis CE. Macrophage regulation of tumor responses to anticancer therapies. Cancer Cell (2013) 23:277-86. doi: 10.1016/j.ccr.2013.02.013

9. Keirsse J, Van Damme H, Van Ginderachter JA, Laoui D. Exploiting tumorassociated dendritic cell heterogeneity for novel cancer therapies. J Leukoc Biol. (2017) 102:317-24. doi: 10.1189/jlb.4MR1116-466R

10. Movahedi K, Laoui D, Gysemans C, Baeten M, Stangé G, Van Bossche J Den, et al. Different tumor microenvironments contain functionally distinct subsets of macrophages derived from Ly6C(high) monocytes. Cancer Res. (2010) 70:5728-39. doi: 10.1158/0008-5472.CAN09-4672

11. Elpek KG, Cremasco V, Shen H, Harvey CJ, Wucherpfennig KW, Goldstein DR. The tumor microenvironment shapes lineage, transcriptional, and functional diversity of infiltrating myeloid cells. Cancer Immunol Res. (2014) 2:655-67. doi: 10.1158/2326-6066.CIR13-0209

12. Kiss M, Van Gassen S, Movahedi K, Saeys Y, Laoui D. Myeloid cell heterogeneity in cancer: not a single cell alike. Cell Immunol. (2018) 330:188201. doi: 10.1016/j.cellimm.2018.02.008

13. Zappasodi R, Merghoub T, Wolchok JD. Emerging concepts for immune checkpoint blockade-based combination therapies. Cancer Cell (2018) 33:581-98. doi: 10.1016/j.ccell.2018.03.005 
14. D'Aloia MM, Zizzari IG, Sacchetti B, Pierelli L, Alimandi M. CAR-T cells: the long and winding road to solid tumors review-article. Cell Death Dis. (2018) 9:282. doi: 10.1038/s41419-018-0278-6

15. Kirkin AF, Dzhandzhugazyan KN, Guldberg P, Fang JJ, Andersen RS, Dahl C, et al. Adoptive cancer immunotherapy using DNA-demethylated $\mathrm{T}$ helper cells as antigen-presenting cells. Nat Commun. (2018) 9:1-12. doi: 10.1038/s41467-018-03217-9

16. Sharma P, Allison JP. The future of immune checkpoint therapy. Science (2015) 348:56-61. doi: 10.1126/science.aaa8172

17. Syn NL, Teng MWL, Mok TSK, Soo RA. De-novo and acquired resistance to immune checkpoint targeting. Lancet Oncol. (2017) 18:e731-41. doi: 10.1016/S1470-2045(17)30607-1

18. Wynn TA, Chawla A, Pollard JW. Origins and hallmarks of macrophages: development, homeostasis, and disease. Nature (2013) 496:445-55. doi: 10.1038/nature12034

19. Guilliams M, Scott CL. Does niche competition determine the origin of tissue-resident macrophages? Nat Rev Immunol. (2017) 17:451-60. doi: $10.1038 /$ nri. 2017.42

20. Ginhoux F, Guilliams M. Tissue-resident macrophage ontogeny and homeostasis. Immunity (2016) 44:439-49. doi: 10.1016/j.immuni.2016.02.024

21. Ruffell B, Coussens LM. Macrophages and therapeutic resistance in cancer. Cancer Cell (2015) 27:462-72. doi: 10.1016/j.ccell.2015.02.015

22. Bolli E, Movahedi K, Laoui D, Van Ginderachter JA. Novel insights in the regulation and function of macrophages in the tumor microenvironment. Curr Opin Oncol. (2017) 29:55-61. doi: 10.1097/CCO.0000000000000344

23. Bowman RL, Klemm F, Akkari L, Pyonteck SM, Quail DF, Dhara $S$, et al. Macrophage ontogeny underlies differences in tumorspecific education in brain malignancies. Cell Rep. (2017) 17:2445-59. doi: 10.1016/j.celrep.2016.10.052

24. Zhu Y, Herndon JM, Sojka DK, Kim KW, Knolhoff BL, Zuo C, et al. Tissueresident macrophages in pancreatic ductal adenocarcinoma originate from embryonic hematopoiesis and promote tumor progression. Immunity (2017) 47:323-38. doi: 10.1016/j.immuni.2017.07.014

25. Laoui D, Van Overmeire E, Conza GD, Aldeni C, Keirsse J, Morias $\mathrm{Y}$, et al. Tumor hypoxia does not drive differentiation of tumorassociated macrophages but rather fine-tunes the M2-like macrophage population. Cancer Res. (2014) 74:24-30. doi: 10.1158/0008-5472.CAN13-1196

26. Pucci F, Venneri MA, Biziato D, Nonis A, Moi D, Sica A, et al. A distinguishing gene signature shared by tumor-infiltrating Tie2-expressing monocytes, blood "resident" monocytes, and embryonic macrophages suggests common functions and developmental relationships. Blood (2009) 114:901-14. doi: 10.1182/blood-2009-01-200931

27. Zheng X, Turkowski K, Mora J, Brüne B, Seeger W, Weigert A, et al. Redirecting tumor-associated macrophages to become tumoricidal effectors as a novel strategy for cancer therapy. Oncotarget (2015) 8:48436-52. doi: 10.18632/oncotarget.17061

28. Petty AJ, Yang Y. Tumor-associated macrophages: implications in cancer immunotherapy. Immunotherapy (2017) 9:289-302. doi: 10.2217/imt-2016-0135

29. Narhendorf M, Swirski FK. Abandoning M1/M2 for a network model of macrophage function. Circ Res. (2016) 119:414-7. doi: 10.1161/CIRCRESAHA.116.309194

30. Azizi E, Carr AJ, Plitas G, Cornish AE, Konopacki C, Prabhakaran S, et al. Single-cell immune map of breast carcinoma reveals diverse phenotypic states driven by the tumor microenvironment. Cell (2017) 174:221994. doi: 10.1016/j.cell.2018.05.060

31. Chevrier S, Levine JH, Zanotelli VRT, Silina K, Schulz D, Bacac M, et al. An immune atlas of clear cell renal cell carcinoma. Cell (2017) 169:736-49. doi: 10.1016/j.cell.2017.04.016

32. Lambrechts D, Wauters E, Boeckx B, Aibar S, Nittner D, Burton O, et al. Phenotype molding of stromal cells in the lung tumor microenvironment. Nature (2018) 24:1277-89. doi: 10.1038/s41591-018-0096-5

33. Germano G, Frapolli R, Belgiovine C, Anselmo A, Pesce S, Liguori M, et al. Role of macrophage targeting in the antitumor activity of trabectedin. Cancer Cell (2013) 23:249-62. doi: 10.1016/j.ccr.2013.01.008
34. Borgoni S, Iannello A, Cutrupi S, Allavena P, D'Incalci M, Novelli $\mathrm{F}$, et al. Depletion of tumor-associated macrophages switches the epigenetic profile of pancreatic cancer infiltrating $\mathrm{T}$ cells and restores their anti-tumor phenotype. Oncoimmunology (2018) 7:e1393596. doi: 10.1080/2162402X.2017.1393596

35. Krug S, Abbassi R, Griesmann H, Sipos B, Wiese D, Rexin P, et al. Therapeutic targeting of tumor-associated macrophages in pancreatic neuroendocrine tumors. Int J Cancer (2018) 143:1806-16. doi: 10.1002/ijc.31562

36. Dhupkar P, Gordon N, Stewart J, Kleinerman ES. Anti-PD-1 therapy redirects macrophages from an $\mathrm{M} 2$ to an $\mathrm{M} 1$ phenotype inducing regression of OS lung metastases. Cancer Med. (2018) 46:1141-2. doi: $10.1002 /$ cam 4.1518

37. Niu M, Valdes S, Naguib YW, Hursting SD, Cui Z. Tumor-associated macrophage-mediated targeted therapy of triple-negative breast cancer. Mol Pharm. (2016) 13:1833-42. doi: 10.1021/acs.molpharmaceut. 5 b00987

38. Movahedi K, Schoonooghe S, Laoui D, Houbracken I, Waelput W, Breckpot $\mathrm{K}$, et al. Nanobody-based targeting of the macrophage mannose receptor for effective in vivo imaging of tumor-associated macrophages. Cancer Res. (2012) 72:4165-77. doi: 10.1158/0008-5472.CAN-11-2994

39. Blykers A, Schoonooghe S, Xavier C, D'hoe K, Laoui D, D’Huyvetter M, et al. PET imaging of macrophage mannose receptor-expressing macrophages in tumor stroma using 18F-radiolabeled camelid single-domain antibody fragments. J Nucl Med. (2015) 56:1265-71. doi: 10.2967/jnumed.115. 156828

40. Nuhn L, Bolli E, Massa S, Vandenberghe I, Movahedi K, Devreese $\mathrm{B}$, et al. Targeting protumoral tumor-associated macrophages with nanobody-functionalized nanogels through strain promoted azide alkyne cycloaddition ligation. Bioconjug Chem. (2018) 29:2394-405. doi: 10.1021/acs.bioconjchem.8b00319

41. Moisan F, Francisco EB, Brozovic A, Duran GE, Wang YC, Chaturvedi $\mathrm{S}$, et al. Enhancement of paclitaxel and carboplatin therapies by CCL2 blockade in ovarian cancers. Mol Oncol. (2014) 8:1-9. doi: 10.1016/j.molonc.2014.03.016

42. Zollo M, Di Dato V, Spano D, De Martino D, Liguori L, Marino N, et al. Targeting monocyte chemotactic protein-1 synthesis with bindarit induces tumor regression in prostate and breast cancer animal models. Clin Exp Metastasis (2012) 29:585-601. doi: 10.1007/s10585-012-9473-5

43. Ries CH, Cannarile MA, Hoves S, Benz J, Wartha K, Runza V, et al. Targeting tumor-associated macrophages with anti-CSF-1R antibody reveals a strategy for cancer therapy. Cancer Cell (2014) 25:846-59. doi: 10.1016/j.ccr.2014.05.016

44. Laoui D, van Overmeire E, de Baetselier P, van Ginderachter JA, Raes G. Functional relationship between tumor-associated macrophages and macrophage colony-stimulating factor as contributors to cancer progression. Front Immunol. (2014) 5:1-15. doi: 10.3389/fimmu.2014. 00489

45. Cannarile MA, Weisser M, Jacob W, Jegg A-M, Ries CH, Rüttinger D. Colony-stimulating factor 1 receptor (CSF1R) inhibitors in cancer therapy. J Immunother Cancer (2017) 5:53. doi: 10.1186/s40425-0170257-y

46. Pyonteck SM, Akkari L, Schuhmacher AJ, Bowman RL, Sevenich L, Quail DF, et al. CSF-1R inhibition alters macrophage polarization and blocks glioma progression. Nat Med. (2013) 19:1264-72. doi: 10.1038/nm.3337

47. Van Overmeire E, Stijlemans B, Heymann F, Keirsse J, Morias Y, Elkrim Y, et al. M-CSF and GM-CSF receptor signaling differentially regulate monocyte maturation and macrophage polarization in the tumor microenvironment. Cancer Res. (2016) 76:35-42. doi: 10.1158/0008-5472.CAN-15-0869

48. Mitchem JB, Brennan DJ, Knolhoff BL, Belt BA, Zhu Y, Sanford $\mathrm{DE}$, et al. Targeting tumor-infiltrating macrophages decreases tumorinitiating cells, relieves immunosuppression and improves chemotherapeutic responses. Cancer Res. (2013) 73:1128-41. doi: 10.1158/0008-5472.CAN$12-2731$

49. Mantovani A, Marchesi F, Malesci A, Laghi L. Tumor-associated macrophages as treatment targets in oncology. Nat Rev Clin Oncol. (2018) 14:399-416. doi: 10.1038/nrclinonc.2016.217 
50. Kaneda MM, Messer KS, Ralainirina N, Li H, Leem CJ, Gorjestani S, et al. $\mathrm{PI} 3 \mathrm{~K} \gamma$ is a molecular switch that controls immune suppression. Nature (2016) 539:437-42. doi: 10.1038/nature19834

51. De Henau O, Rausch M, Winkler D, Campesato LF, Liu C, Cymerman DH, et al. Overcoming resistance to checkpoint blockade therapy by targeting PI3K- $\gamma$ in myeloid cells. Nature (2016) 539:443-7. doi: 10.1038/nature 20554

52. Poh AR, Love CG, Masson F, Preaudet A, Tsui C, Whitehead L, et al. Inhibition of hematopoietic cell kinase activity suppresses myeloid cell-mediated colon cancer progression. Cancer Cell (2017) 31:563-75. doi: 10.1016/j.ccell.2017.03.006

53. Guerriero JL, Sotayo A, Ponichtera HE, Castrillon JA, Pourzia AL, Schad S, et al. Class IIa HDAC inhibition reduces breast tumours and metastases through anti-tumour macrophages. Nature (2017) 543:428-32. doi: 10.1038/nature21409

54. Singh M, Khong H, Dai Z, Huang X-F, Wargo JA, Cooper ZA, et al. Effective innate and adaptive anti-melanoma immunity through localized TLR-7/8 activation. J Immunol. (2014) 193:4722-31. doi: 10.4049/jimmunol. 1401160

55. Dewan MZ, Vanpouille-Box C, Kawashima N, DiNapoli S, Babb JS, Formenti SC, et al. Synergy of topical Toll-Like Receptor 7 agonist with radiation and low dose cyclophosphamide in a mouse model of cutaneous breast cancer. Clin Cancer Res. (2012) 18:6668-78. doi: 10.1158/1078-0432.CCR12-0984

56. Rodell CB, Arlauckas SP, Cuccarese MF, Garris CS, Li R, Ahmed MS, et al. TLR7/8-agonist-loaded nanoparticles promote the polarization of tumourassociated macrophages to enhance cancer immunotherapy. Nat Biomed Eng. (2018) 1:1-11. doi: 10.1038/s41551-018-0236-8

57. Shime H, Matsumoto M, Oshiumi H, Tanaka S, Nakane A, Iwakura Y, et al. Toll-like receptor 3 signaling converts tumor-supporting myeloid cells to tumoricidal effectors. Proc Natl Acad Sci USA. (2012) 109:2066-71. doi: 10.1073/pnas.1113099109

58. Yuan R, Li S, Geng H, Wang X, Guan Q, Li X, et al. Reversing the polarization of tumor-associated macrophages inhibits tumor metastasis. Int Immunopharmacol. (2017) 49:30-7. doi: 10.1016/j.intimp.2017. 05.014

59. Miyamoto N, Mochizuki S, Fujii S, Yoshida K, Sakurai K. Adjuvant activity enhanced by cross-linked CpG-Oligonucleotides in $\beta$-Glucan nanogel and its antitumor effect. Bioconjug Chem. (2017) 28:565-73. doi: 10.1021/acs.bioconjchem.6b00675

60. Sato-Kaneko F, Yao S, Ahmadi A, Zhang SS, Hosoya T, Kaneda MM, et al. Combination immunotherapy with TLR agonists and checkpoint inhibitors suppresses head and neck cancer. JCI Insight (2017) 2:e93397. doi: 10.1172/jci.insight.93397

61. Müller E, Christopoulos PF, Halder S, Lunde A, Beraki K, Speth $\mathrm{M}$, et al. Toll-like receptor ligands and interferon- $\gamma$ synergize for induction of antitumor M1 macrophages. Front Immunol. (2017) 8:1383. doi: 10.3389/fimmu.2017.01383

62. Felgner S, Kocijancic D, Frahm M, Weiss S. Bacteria in cancer therapy: renaissance of an old concept. Int J Microbiol. (2016) 2016:1-14. doi: $10.1155 / 2016 / 8451728$

63. Kaimala S, Al-sbiei A, Cabral-marques O, Fernandez- MJ. Attenuated bacteria as immunotherapeutic tools for cancer treatment. Front Immunol. (2018) 8:136. doi: 10.3389/fonc.2018.00136

64. Cai X, Yin Y, Li N, Zhu D, Zhang J, Zhang C-Y, et al. Re-polarization of tumor-associated macrophages to pro-inflammatory M 1 macrophages. $J$ Mol Cell Biol. (2012) 4:341-3. doi: 10.1093/jmcb/mjs044

65. Wang P, Xu LJ, Qin JJ, Zhang L, Zhuang GH. MicroRNA-155 inversely correlates with esophageal cancer progression through regulating tumorassociated macrophage FGF2 expression. Biochem Biophys Res Commun. 503:452-8. doi: 10.1016/j.bbrc.2018.04.094

66. Chaudhuri AA, Yick-Lun So A, Sinha N, Gibson WSJ, Taganov $\mathrm{KD}$, O'Connell RM et al. Mir-125b potentiates macrophage activation. J Immunol. (2011) 187:5062-8. doi: 10.4049/jimmunol. 1102001

67. Parayath NN, Parikh A, Amiji MM. Repolarization of tumor-associated macrophages in a genetically engineered non-small cell lung cancer model by intraperitoneal administration of hyaluronic acid-based nanoparticles encapsulating MicroRNA-125b. Nano Lett. 18:3571-9. doi: 10.1021/acs.nanolett.8b00689

68. Squadrito ML, Pucci F, Magri L, Moi D, Gilfillan GD, Ranghetti A, et al. MiR511-3p modulates genetic programs of tumor-associated macrophages. Cell Rep. (2012) 1:141-54. doi: 10.1016/j.celrep.2011.12.005

69. Baer C, Squadrito ML, Laoui D, Thompson D, Hansen SK, Kiialainen A, et al. Suppression of microRNA activity amplifies IFN- $\gamma$-induced macrophage activation and promotes anti-tumour immunity. Nat Cell Biol. (2016) 18:790-802. doi: 10.1038/ncb3371

70. De Palma M, Biziato D, Petrova TV. Microenvironmental regulation of tumour angiogenesis. Nat Rev Cancer (2017) 17:457-74. doi: $10.1038 /$ nrc.2017.51

71. Carmeliet P, Jain RK. Principles and mechanisms of vessel normalization for cancer and other angiogenic diseases. Nat Rev Drug Discov. (2011) 10:417-27. doi: 10.1038/nrd3455

72. Downey CM, Aghaei M, Schwendener RA, Jirik FR. DMXAA causes tumor site-specific vascular disruption in murine non-small cell lung cancer, and like the endogenous non-canonical cyclic dinucleotide STING agonist, $2^{\prime} 3^{\prime}$ cGAMP, induces M2 macrophage repolarization. PLoS ONE (2014) 9:e99988. doi: 10.1371/journal.pone.0099988

73. Smolarczyk R, Cichon T, Pilny E, Jarosz-Biej M, Poczkaj A, Kułach N, et al. Combination of anti-vascular agent-DMXAA and HIF-1 $\alpha$ inhibitordigoxin inhibits the growth of melanoma tumors. Sci Rep. (2018) 8:1-9. doi: 10.1038/s41598-018-25688-y

74. Lei X, Chen M, Li X, Huang M, Nie Q, Ma N, et al. A vascular disrupting agent overcomes tumor multidrug resistance by skewing macrophage polarity toward the M1 phenotype. Cancer Lett. (2018) 418:239-49. doi: 10.1016/j.canlet.2018.01.016

75. Kloepper J, Riedemann L, Amoozgar Z, Seano G, Susek K, Yu V, et al. Ang2/VEGF bispecific antibody reprograms macrophages and resident microglia to anti-tumor phenotype and prolongs glioblastoma survival. Proc Natl Acad Sci USA. (2016) 113:4476-81. doi: 10.1073/pnas.1525360113

76. Peterson TE, Kirkpatrick ND, Huang Y, Farrar CT, Marijt KA, Kloepper J, et al. Dual inhibition of Ang-2 and VEGF receptors normalizes tumor vasculature and prolongs survival in glioblastoma by altering macrophages. Proc Natl Acad Sci USA. (2016) 113:4470-75. doi: 10.1073/pnas.1525349113

77. Zhu X, Yang J, Gao Y, Wu C, Yi L, Li G, et al. The dual effects of a novel peptibody on angiogenesis inhibition and M2 macrophage polarization on sarcoma. Cancer Lett. (2018) 416:1-10. doi: 10.1016/j.canlet.2017. 10.043

78. Schmittnaegel M, Rigamonti N, Kadioglu E, Cassará A, Rmili CW, Kiialainen A, et al. Dual angiopoietin-2 and VEGFA inhibition elicits antitumor immunity that is enhanced by PD-1 checkpoint blockade. Sci Transl Med. (2017) 9:eaak9670. doi: 10.1126/scitranslmed.aak9670

79. Rolny C, Mazzone M, Tugues S, Laoui D, Johansson I, Coulon C, et al. HRG inhibits tumor growth and metastasis by inducing macrophage polarization and vessel normalization through downregulation of PlGF. Cancer Cell (2011) 19:31-44. doi: 10.1016/j.ccr.2010.11.009

80. Beatty GL, Chiorean EG, Fishman MP, Saboury B, Teitelbaum R, Sun W, et al. CD40 agonists alter tumor stroma and show efficacy against pancreatic carcinoma in mice and humans. Science (2011) 331:1612-6. doi: 10.1126/science. 1198443

81. Hoves S, Ooi C-H, Wolter C, Sade H, Bissinger S, Schmittnaegel M, et al. Rapid activation of tumor-associated macrophages boosts preexisting tumor immunity. J Exp Med. (2018) 215:859-76. doi: 10.1084/jem.20171440

82. Perry CJ, Muñoz-Rojas AR, Meeth KM, Kellman LN, Amezquita RA, Thakral D, et al. Myeloid-targeted immunotherapies act in synergy to induce inflammation and antitumor immunity. J Exp Med. (2018) 215:877-93. doi: 10.1084/jem.20171435

83. Georgoudaki AM, Prokopec KE, Boura VF, Hellqvist E, Sohn S, Östling J, et al. Reprogramming tumor-associated macrophages by antibody targeting inhibits cancer progression and metastasis. Cell Rep. (2016) 15:2000-11. doi: 10.1016/j.celrep.2016.04.084

84. Carmona-Fontaine C, Deforet M, Akkari L, Thompson CB, Joyce JA, Xavier JB. Metabolic origins of spatial organization in the tumor microenvironment. Proc Natl Acad Sci USA. (2017) 114:2934-9. doi: 10.1073/pnas.1700600114

85. Casazza A, Laoui D, Wenes M, Rizzolio S, Bassani N, Mambretti M, et al. Impeding macrophage entry into hypoxic tumor areas by Sema3A/Nrp1 
signaling blockade inhibits angiogenesis and restores antitumor immunity. Cancer Cell (2013) 24:695-709. doi: 10.1016/j.ccr.2013.11.007

86. Edris B, Weiskopf K, Volkmer AK, Volkmer J-P, Willingham SB, ContrerasTrujillo $\mathrm{H}$, et al. Antibody therapy targeting the CD47 protein is effective in a model of aggressive metastatic leiomyosarcoma. Proc Natl Acad Sci USA. (2012) 109:6656-61. doi: 10.1073/pnas.1121629109

87. Sikic BI, Narayanan S, Colevas D, Padda SK, Fisher GA, Supan D, et al. A first-in-human, first-in-class phase I trial of the anti-CD47 antibody Hu5F9-G4 in patients with advanced cancers. J Clin Oncol. (2017) 34:3019. doi: 10.1200/JCO.2016.34.15_suppl.3019

88. Weiskopf K, Ring AM, Ho CCM, Volkmer J, Levin A. M., Volkmer A. K., et al. Engineered SIRPa variants as immunotherapeutic adjuvants to anticancer antibodies. Science (2013) 341:88-91. doi: $10.1126 /$ science. 1238856

89. Chen D, Xie J, Fiskesund R, Dong W, Liang X, Lv J, et al. Chloroquine modulates antitumor immune response by resetting tumor-associated macrophages toward M1 phenotype. Nat Commun. (2018) 8:1-15. doi: 10.1038/s41467-018-03225-9

90. Chakraborty P, Chatterjee S, Ganguly A, Saha P, Adhikary A, Das T, et al. Reprogramming of TAM toward proimmunogenic type through regulation of MAP kinases using a redox-active copper chelate. J Leukoc Biol. (2012) 91:1-11. doi: 10.1189/jlb.0611287

91. Guilliams M, Dutertre CA, Scott CL, McGovern N, Sichien D, Chakarov S, et al. Unsupervised high-dimensional analysis aligns dendritic cells across tissues and species. Immunity (2016) 45:669-84. doi: 10.1016/j.immuni.2016.08.015

92. Merad M, Sathe P, Helft J, Miller J, Mortha A. The dendritic cell lineage: ontogeny and function of dendritic cells and their subsets in the steady state and the inflamed setting. Аnnu Rev Immunol. (2013) 31:1-16. doi: 10.1146/annurev-immunol-020711-074950

93. Ginhoux F, Jung S. Monocytes and macrophages: developmental pathways and tissue homeostasis. Nat Rev Immunol. (2014) 14:392-404. doi: $10.1038 /$ nri3671

94. Laoui D, Keirsse J, Morias Y, Van Overmeire E, Geeraerts X, Elkrim Y, et al. The tumour microenvironment harbours ontogenically distinct dendritic cell populations with opposing effects on tumour immunity. Nat Commun. (2016) 7:1-17. doi: 10.1038/ncomms13720

95. Villani A, Satija R, Reynolds G, Sarkizova S, Shekhar K, Fletcher J, et al. Single-cell RNA-seq reveals new types of human blood dendritic cells, monocytes and progenitors. Science (2017) 356:1-31. doi: $10.1126 /$ science.aah4573

96. Segura E, Touzot M, Bohineust A, Cappuccio A, Chiocchia G, Hosmalin A, et al. Human inflammatory dendritic cells induce Th17 cell differentiation. Immunity (2013) 38:336-48. doi: 10.1016/j.immuni.2012.10.018

97. Swiecki M, Colonna M. The multifaceted biology of plasmacytoid dendritic cells. Nat Rev Immunol. (2015) 15:471-85. doi: 10.1038/nri3865

98. Bakdash G, Buschow SI, Gorris MAJ, Halilovic A, Hato SV, Sko ld AE, et al. Expansion of a BDCA1+CD14+ myeloid cell population in melanoma patients may attenuate the efficacy of dendritic cell vaccines. Cancer Res. (2016) 76:4332-46. doi: 10.1158/0008-5472.CAN-15-1695

99. Bennaceur K, Chapman J, Brikci-Nigassa L, Sanhadji K, Touraine J louis, Portoukalian J. Dendritic cells dysfunction in tumour environment. Cancer Lett. (2008) 272:186-96. doi: 10.1016/j.canlet.2008.05.017

100. Conejo-Garcia JR, Rutkowski MR, Cubillos-Ruiz JR. State-of-the-art of regulatory dendritic cells in cancer. Pharmacol Ther. (2016) 164:97-104. doi: 10.1016/j.pharmthera.2016.04.003

101. Broz ML, Binnewies M, Boldajipour B, Nelson AE, Pollack JL, Erle DJ, et al. Dissecting the tumor myeloid compartment reveals rare activating antigenpresenting cells critical for T cell immunity. Cancer Cell (2014) 26:638-52. doi: 10.1016/j.ccell.2014.09.007

102. Lavin Y, Kobayashi S, Leader A, Amir E-AD, Elefant N, Bigenwald C, et al. Innate immune landscape in early lung adenocarcinoma by paired single-cell analyses. Cell (2017) 169:750-65. doi: 10.1016/j.cell.2017.04.014

103. Garg AD, Coulie PG, Van den Eynde BJ, Agostinis P. Integrating nextgeneration dendritic cell vaccines into the current cancer immunotherapy landscape. Trends Immunol. (2017) 38:577-93. doi: 10.1016/j.it.2017.05.006

104. Garg AD, Perez MV, Schaaf M, Agostinis P, Zitvogel L, Kroemer $G$, et al. Trial watch: dendritic cell-based anticancer therapy.
Oncoimmunology (2017) 6:e1328341. doi: 10.4161/21624011.2014. 963424

105. Ahmed S, Bae Y-S. Dendritic cell-based therapeutic cancer vaccines: past, present and future. Clin Exp Vaccine Res. (2014) 3:113-6. doi: 10.7774/cevr.2014.3.2.113

106. Bol KF, Schreibelt G, Gerritsen WR, De Vries IJM, Figdor CG. Dendritic cellbased immunotherapy: state of the art and beyond. Clin Cancer Res. (2016) 22:1897-906. doi: 10.1158/1078-0432.CCR-15-1399

107. Cheever MA, Higano CS. PROVENGE (sipuleucel-T) in prostate cancer: the first FDA-approved therapeutic cancer vaccine. Clin Cancer Res. (2011) 17:3520-6. doi: 10.1158/1078-0432.CCR-10-3126

108. Abraham RS, Mitchell DA. Gene-modified dendritic cell vaccines for cancer. Cytotherapy (2016) 18:1446-55. doi: 10.1016/j.jcyt.2016.09.009

109. Jeught K Van der, Bialkowski L, Daszkiewicz L, Broos K, Goyvaerts C, Renmans D, et al. Targeting the tumor microenvironment to enhance antitumor immune responses. Oncotarget (2015) 6:1359-81. doi: 10.18632/oncotarget.3204

110. Garg AD, Vandenberk L, Koks C, Verschuere T, Boon L. Dendritic cell vaccines based on immunogenic cell death elicit danger signals and $\mathrm{T}$ cell-driven rejection of high-grade glioma Dendritic cell vaccines based on immunogenic cell death elicit danger signals and $\mathrm{T}$ celldriven rejection of high-grade glio. Immunotherapy (2016) 8:1-16. doi: 10.1126/scitranslmed.aae0105

111. Garg AD, Krysko DV, Verfaillie T, Kaczmarek A, Ferreira GB, Marysael $\mathrm{T}$, et al. A novel pathway combining calreticulin exposure and ATP secretion in immunogenic cancer cell death. EMBO J. (2012) 31:1062-79. doi: 10.1038/emboj.2011.497

112. Hradilova N, Sadilkova L, Palata O, Mysikova D, Mrazkova H, Lischke $\mathrm{R}$, et al. Generation of dendritic cell-based vaccine using high hydrostatic pressure for non-small cell lung cancer immunotherapy. PLOS ONE (2017) 12: e0171539. doi: 10.1371/journal.pone.0171539

113. Van Lint S, Renmans D, Broos K, Goethals L, Maenhout S, Benteyn D, et al. Intratumoral delivery of TriMix mRNA results in T-cell activation by cross-presenting dendritic cells. Cancer Immunol Res. (2016) 4:146-56. doi: 10.1158/2326-6066.CIR-15-0163

114. Seremet T, Koch A, Jansen Y, Schreuer M, Wilgenhof S, Marmol $\mathrm{V}$, et al. Molecular and epigenetic features of melanomas and tumor immune microenvironment linked to durable remission to ipilimumabbased immunotherapy in metastatic patients. J Transl Med. (2016) 14:1-14. doi: 10.1186/s12967-016-0990-x

115. Wilgenhof S, Corthals J, Heirman C, Van Baren N, Lucas S, Kvistborg $\mathrm{P}$, et al. Phase II study of autologous monocyte-derived mRNA electroporated dendritic cells (TriMixDC-MEL) plus ipilimumab in patientswith pretreated advanced melanoma. J Clin Oncol. (2016) 34:1330-8. doi: 10.1200/JCO.2015.63.4121

116. Ma DY, Clark EA. The role of CD40 and CD40L in dendritic cells. Semin Immunol. (2009) 21:265-72.

117. Lapteva N, Seethammagari MR, Hanks BA, Jiang H, Levitt JM, Slawin $\mathrm{KM}$, et al. Enhanced activation of human dendritic cells by inducible CD40 and toll-like receptor-4 ligation. Cancer Res. (2007) 67:10528-37. doi: 10.1158/0008-5472.CAN-07-0833

118. Stone GW, Barzee S, Snarsky V, Santucci C, Tran B, Langer R, et al. Nanoparticle-delivered multimeric soluble CD40L DNA combined with tolllike receptor agonists as a treatment for melanoma. PLoS ONE (2009) 4:e7334. doi: 10.1371/journal.pone.0007334

119. Onai N, Obata-Onai A, Schmid MA, Ohteki T, Jarrossay D, Manz MG. Identification of clonogenic common Flt3+M-CSFR+ plasmacytoid and conventional dendritic cell progenitors in mouse bone marrow. Nat Immunol. (2007) 8:1207-16. doi: 10.1038/ni1518

120. Riediger C, Wingender G, Knolle P, Aulmann S, Stremmel W, Encke J. Fmslike tyrosine kinase 3 receptor ligand (Flt3L)-based vaccination administered with an adenoviral vector prevents tumor growth of colorectal cancer in a BALB/c mouse model. J Cancer Res Clin Oncol. (2013) 139:2097-110. doi: $10.1007 / \mathrm{s} 00432-013-1532-\mathrm{z}$

121. Tel J, Aarntzen EHJG, Baba T, Schreibelt G, Schulte BM, Benitez-Ribas D et al. Natural human plasmacytoid dendritic cells induce antigen-specific T-Cell responses in melanoma patients. Cancer Res. (2013) 73:1063-75. doi: 10.1158/0008-5472.CAN-12-2583 
122. Schreibelt G, Bol KF, Westdorp H, Wimmers F, Aarntzen EHJG, DuivemanDe Boer T, et al. Effective clinical responses in metastatic melanoma patients after vaccination with primary myeloid dendritic cells. Clin Cancer Res. (2016) 22:2155-66. doi: 10.1158/1078-0432.CCR-15-2205

123. Davis MB, Vasquez-Dunddel D, Fu J, Albesiano E, Pardoll D, Kim YJ. Intratumoral administration of TLR4 agonist absorbed into a cellular vector improves antitumor responses. Clin Cancer Res. (2011) 17:3984-92. doi: 10.1158/1078-0432.CCR-10-3262

124. Salmon H, Idoyaga J, Rahman A, Leboeuf M, Remark R, Jordan S, et al. Expansion and activation of $\mathrm{CD} 103+$ dendritic cell progenitors at the tumor site enhances tumor responses to therapeutic PD-L1 and BRAF inhibition. Immunity (2016) 44:924-38. doi: 10.1016/j.immuni.2016.03.012

125. Luo Z, Wang C, Yi H, Li P, Pan H, Liu L, Cai L, Ma Y. Nanovaccine loaded with poly I: C and STAT3 siRNA robustly elicits anti-tumor immune responses through modulating tumor-associated dendritic cells in vivo. Biomaterials (2015) 38:50-60. doi: 10.1016/j.biomaterials.2014.10.050

126. Rosalia RA, Cruz LJ, van Duikeren S, Tromp AT, Silva AL, Jiskoot $\mathrm{W}$, et al. CD40-targeted dendritic cell delivery of PLGA-nanoparticle vaccines induce potent anti-tumor responses. Biomaterials (2015) 40:88-97. doi: 10.1016/j.biomaterials.2014.10.053

127. Cochran AJ, Morton DL, Stern S, Lana AM, Essner R, Wen DR. Sentinel lymph nodes show profound downregulation of antigen-presenting cells of the paracortex: implications for tumor biology and treatment. Mod Pathol. (2001) 14:604-8. doi: 10.1038/modpathol.3880358

128. Sluijter BJR, van den Hout MFCM, Koster BD, van Leeuwen PAM, Schneiders FL, van de Ven R, et al. Arming the melanoma sentinel lymph node through local administration of $\mathrm{CpG}-\mathrm{B}$ and GM-CSF: recruitment and activation of $\mathrm{BDCA} 3 / \mathrm{CD} 141+$ dendritic cells and enhanced cross-presentation. Cancer Immunol Res. (2015) 3:495-505. doi: 10.1158/2326-6066.CIR-14-0165

129. Mould RC, AuYeung AWK, Van Vloten JP, Susta L, Mutsaers AJ, Petrik JJ, et al. Enhancing immune responses to cancer vaccines using multi-site injections. Sci Rep. (2017) 7:3-10. doi: 10.1038/s41598-017-08665-9

130. Spitzer MH, Carmi Y, Reticker-Flynn NE, Kwek SS, Madhireddy $\mathrm{D}$, Martins MM, et al. Systemic immunity is required for effective cancer immunotherapy. Anal Chem. (2015) 25:368-79. doi: 10.1016/j.cell.2016.12.022

131. Kranz LM, Diken M, Haas H, Kreiter S, Loquai C, Reuter KC, et al. Systemic RNA delivery to dendritic cells exploits antiviral defence for cancer immunotherapy. Nature (2016) 534:396-401. doi: 10.1038/nature18300

132. Böttcher JP, Bonavita E, Chakravarty P, Blees H, Cabeza-Cabrerizo $\mathrm{M}$, Sammicheli S, et al. NK cells stimulate recruitment of $\mathrm{cDC} 1$ into the tumor microenvironment promoting cancer immune control. Cell (2018) 172:1022-8.e14. doi: 10.1016/j.cell.2018. 01.004

133. Sánchez-Paulete AR, Teijeira A, Cueto FJ, Garasa S, Pérez-Gracia JL, Sánchez-Arráez A, et al. Antigen cross-presentation and T-cell cross-priming in cancer immunology and immunotherapy. Ann Oncol. (2017) 28:xii44xii55. doi: $10.1093 / \mathrm{annonc} / \mathrm{mdx} 237$

134. Shen M, Ren X. New insights into the biological impacts of immune cell-derived exosomes within the tumor environment. Cancer Lett. (2018) 431:115-22. doi: 10.1016/j.canlet.2018.05.040

135. Lu Z, Zuo B, Jing R, Gao X, Rao Q, Liu Z, et al. Dendritic cell-derived exosomes elicit tumor regression in autochthonous hepatocellular carcinoma mouse models. J Hepatol. (2017) 67:739-48. doi: 10.1016/j.jhep.2017.05.019

136. Chen Gang EL. Chemoimmunotherapy:reengineering tumor immunity. Cancer Immunol Immunother. (2013) 33:203-16. doi: $10.1007 / \mathrm{s} 00262-012-1388-0$

137. Ishii H, Chikamatsu K, Igarashi S, Takahashi H, Sakamoto K, Higuchi $\mathrm{H}$, et al. Establishment of synergistic chemoimmunotherapy for head and neck cancer using peritumoral immature dendritic cell injections and low-dose chemotherapies. Transl Oncol. (2018) 11:18-23. doi: 10.1016/j.tranon.2017.11.006

138. Cornelissen R, Hegmans JPJJ, Maat APWM, Kaijen-Lambers MEH, Bezemer $\mathrm{K}$, Hendriks RW, et al. Extended tumor control after dendritic cell vaccination with low-dose cyclophosphamide as adjuvant treatment in patients with malignant pleural mesothelioma. Am J Respir Crit Care Med. (2016) 193:1023-31. doi: 10.1164/rccm.201508-1573OC
139. Coffelt SB, Wellenstein MD, De Visser KE. Neutrophils in cancer: neutral no more. Nat Rev Cancer (2016) 16:431-46. doi: 10.1038/nrc.2016.52

140. Jamieson T, Clarke M, Steele CW, Samuel MS, Neumann J, Jung A, et al. Inhibition of CXCR2 profoundly suppresses inflammationdriven and spontaneous tumorigenesis. J Clin Invest. (2012) 122:3127-44. doi: 10.1172/JCI61067

141. Mouchemore KA, Anderson RL, Hamilton JA. Neutrophils, G-CSF and their contribution to breast cancer metastasis. FEBS J. (2018) 285:665-79. doi: $10.1111 /$ febs.14206

142. Takeshima T, Pop LM, Laine A, Iyengar P, Vitetta ES, Hannan R. Key role for neutrophils in radiation-induced antitumor immune responses: potentiation with G-CSF. Proc Natl Acad Sci USA. (2016) 113:11300-5. doi: 10.1073/pnas.1613187113

143. Ocana A, Nieto-Jiménez C, Pandiella A, Templeton AJ. Neutrophils in cancer: prognostic role and therapeutic strategies. Mol Cancer (2017) 16:1-7. doi: 10.1186/s12943-017-0707-7

144. Moses K, Brandau S. Human neutrophils: their role in cancer and relation to myeloid-derived suppressor cells. Semin Immunol. (2016) 28:187-96. doi: $10.1016 /$ j.smim.2016.03.018

145. Condamine T, Mastio J, Gabrilovich DI. Transcriptional regulation of myeloid-derived suppressor cells. J Leukoc Biol. (2015) 98:913-22. doi: 10.1189/jlb.4RI0515-204R

146. Ibrahim SA, Katara GK, Kulshrestha A, Jaiswal MK, Amin MA, Beaman $\mathrm{KD}$. Breast cancer associated a2 isoform vacuolar ATPase immunomodulates neutrophils: potential role in tumor progression. Oncotarget (2015) 6:3303345. doi: 10.18632/oncotarget.5439

147. Eruslanov EB, Bhojnagarwala PS, Quatromoni JG, Stephen TL, Ranganathan A, Deshpande C, et al. Tumor-associated neutrophils stimulate $\mathrm{T}$ cell responses in early-stage human lung cancer. J Clin Invest. (2014) 124:546680. doi: $10.1172 / \mathrm{JCI} 77053$

148. Templeton AJ, McNamara MG, Šeruga B, Vera-Badillo FE, Aneja P, Ocaña A, Leibowitz-Amit R, et al. Prognostic role of neutrophil-to-lymphocyte ratio in solid tumors: a systematic review and meta-analysis. J Natl Cancer Inst. (2014) 106:dju124. doi: 10.1093/jnci/dju124

149. Yutong H, Xiaoli X, Shumei L, Shan S, Di L, Baoen S. Increased neutrophillymphocyte ratio is a poor prognostic factor in patients with esophageal cancer in a high incidence area in China. Arch Med Res. (2015) 46:557-63. doi: 10.1016/j.arcmed.2015.09.003

150. Najjar M, Agrawal S, Emond JC, Halazun KJ. Pretreatment neutrophillymphocyte ratio: useful prognostic biomarker in hepatocellular carcinoma. J Hepatocell Carcinoma (2018) 5:17-28. doi: 10.2147/JHC.S86792

151. Viola A, Sarukhan A, Bronte V, Molon B. The pros and cons of chemokines in tumor immunology. Trends Immunol. (2012) 33:496-504. doi: 10.1016/j.it.2012.05.007

152. Engblom C, Pfirschke C, Zilionis R, Da Silva Martins J, Bos SA, Courties G, et al. Osteoblasts remotely supply lung tumors with cancer-promoting SiglecFhighneutrophils. Science (2017) 358:eaal5081. doi: $10.1126 /$ science.aal5081

153. Mishalian I, Bayuh R, Eruslanov E, Michaeli J, Levy L, Zolotarov L, et al. Neutrophils recruit regulatory T-cells into tumors via secretion of CCL17a new mechanism of impaired antitumor immunity. Int J Cancer (2014) 135:1178-86. doi: 10.1002/ijc.28770

154. Yan J, Kloecker G, Fleming C, Bousamra M, Hansen R, Hu X, et al. Human polymorphonuclear neutrophils specifically recognize and kill cancerous cells. Oncoimmunology (2014) 3:e950163. doi: 10.4161/15384101.2014.950163

155. Wculek SK, Malanchi I. Neutrophils support lung colonization of metastasis-initiating breast cancer cells. Nature (2015) 528:413-7. doi: $10.1038 /$ nature 16140

156. Bekes EM, Schweighofer B, Kupriyanova TA, Zajac E, Ardi VC, Quigley JP, et al. Tumor-recruited neutrophils and neutrophil TIMP-free MMP9 regulate coordinately the levels of tumor angiogenesis and efficiency of malignant cell intravasation. Am J Pathol. (2011) 179:1455-70. doi: $10.1016 /$ j.ajpath.2011.05.031

157. Jablonska J, Leschner S, Westphal K, Lienenklaus S, Weiss S. Neutrophils responsive to endogenous IFN-b regulate tumor angiogenesis and growth in a mouse tumor model. J Clin Invest. (2010) 120:1151-64. doi: $10.1172 / J C I 37223$ 
158. Benevides L, Da Fonseca DM, Donate PB, Tiezzi DG, De Carvalho DD, De Andrade JM, et al. IL17 promotes mammary tumor progression by changing the behavior of tumor cells and eliciting tumorigenic neutrophils recruitment. Cancer Res (2015) 75:3788-99. doi: 10.1158/0008-5472.CAN-15-0054

159. Fridlender ZG, Sun J, Kim S, Kapoor V, Cheng G, Worthen GS, et al. Polarization of tumor-associated neutrophil (TAN) phenotype by TGF- $\beta$ : "N1" versus "N2" TAN. Cancer Cell (2009) 16:183-94. doi: 10.1016/j.ccr.2009.06.017

160. Andzinski L, Kasnitz N, Stahnke S, Wu CF, Gereke M, Von KöckritzBlickwede M, et al. Type i IFNs induce anti-tumor polarization of tumor associated neutrophils in mice and human. Int J Cancer (2016) 138:1982-93. doi: 10.1002/ijc.29945

161. Pylaeva E, Lang S, Jablonska J. The essential role of type I interferons in differentiation and activation of tumor-associated neutrophils. Front Immunol. (2016) 7:629. doi: 10.3389/fimmu.2016.00629

162. Dvorak HF. Tumors: wounds that do not heal. Similarities between tumor stroma generation and wound healing. N Engl J Med. (1986) 315:1650-9.

163. Souto JC, Vila L, Bru A. Polymorphonuclear neutrophils and cancer: intense and sustained neutrophilia as a treatment against solid tumors. Med Res Rev. (2009) 31:311-63. doi: 10.1002/med.20185

164. Im JH, Tapmeier T, Balathasan L, Gal A, Yameen S, Hill S, et al. GCSF rescues tumor growth and neo-angiogenesis during liver metastasis under host angiopoietin-2 deficiency. Int J Cancer (2013) 132:315-26. doi: 10.1002/ijc.27677

165. Pickup MW, Owens P, Gorska AE, Chytil A, Ye F, Shi C, et al. Development of aggressive pancreatic ductal adenocarcinomas depends on granulocytecolony stimulating factor secretion in carcinoma cells. Cancer Immunol Res. (2017) 5:718-29. doi: 10.1158/2326-6066.CIR-16-0311

166. Li W, Zhang X, Chen Y, Xie Y, Liu J, Feng Q, et al. G-CSF is a key modulator of MDSC and could be a potential therapeutic target in colitis-associated colorectal cancers. Protein Cell (2016) 7:130-40. doi: 10.1007/s13238-015-0237-2

167. Kast RE, Hill QA, Wion D, Mellstedt H, Focosi D, Karpel-Massler G, et al. Glioblastoma-synthesized G-CSF and GM-CSF contribute to growth and immunosuppression: potential therapeutic benefit from dapsone, fenofibrate, and ribavirin. Tumor Biol. (2017) 39:1010428317699797. doi: $10.1177 / 1010428317699797$

168. Granot Z, Henke E, Comen E, King T, Norton L, Benezra R. Tumor entrained neutrophils inhibit seeding in the premetastatic lung. Cancer Cell (2011) 20:300-14. doi: 10.1016/j.ccr.2011. 08.012

169. Bajrami B, Zhu H, Kwak H-J, Mondal S, Hou Q, Geng G, et al. G-CSF maintains controlled neutrophil mobilization during acute inflammation by negatively regulating CXCR2 signaling. J Exp Med. (2016) 213:1999-2018. doi: $10.1084 /$ jem. 20160393

170. Kaunisto A, Henry WS, Montaser-Kouhsari L, Jaminet SC, Oh EY, Zhao L, et al. NFAT1 promotes intratumoral neutrophil infiltration by regulating IL8 expression in breast cancer. Mol Oncol. (2015) 9:1140-54. doi: 10.1016/j.molonc.2015.02.004

171. López-Lago MA, Posner S, Thodima VJ, Molina AM, Motzer RJ, Chaganti R. Neutrophil chemokines secreted by tumor cells mount a lung antimetastatic response during renal cell carcinoma progression. Oncogene (2013) 32:175260. doi: 10.1038/onc.2012.201

172. Patnaik A, Swanson KD, Csizmadia E, Solanki A, Landon-Brace N, Gehring MP, et al. Cabozantinib eradicates advanced murine prostate cancer by activating antitumor innate immunity. Cancer Discov. (2017) 7:750-65. doi: 10.1158/2159-8290.CD-16-0778

173. Lu X, Horner JW, Paul E, Shang X, Troncoso P, Deng P, et al. Effective combinatorial immunotherapy for castration resistant prostate cancer. Nature (2017) 344:1173-8. doi: 10.1038/nature21676

174. Devapatla B, Sharma A, Woo S. CXCR2 inhibition combined with sorafenib improved antitumor and antiangiogenic response in preclinical models of ovarian cancer. PLoS ONE (2015) 10:e0139237. doi: 10.1371/journal.pone. 0139237

175. Glodde N, Bald T, van den Boorn-Konijnenberg D, Nakamura K, O’Donnell JS, Szczepanski S, et al. Reactive neutrophil responses dependent on the receptor tyrosine kinase c-MET limit cancer immunotherapy.
Immunity (2017) 47:789-802.e9. doi: 10.1016/j.immuni.2017. 09.012

176. Finisguerra V, Conza G Di, Matteo M Di, Serneels J, Thompson AAR, Wauters E, et al. MET is required for the recruitment of anti-tumoural neutrophils. Nature (2015) 522:349-53. doi: 10.1038/nature14407

177. Powell DR, Huttenlocher A. Neutrophils in the tumor microenvironment. Trends Immunol. (2016) 37:41-52. doi: 10.1016/j.it.2015.11.008

178. Singhal S, Bhojnagarwala PS, O’Brien S, Moon EK, Garfall AL, Rao A, et al. Origin and role of a subset of tumor-associated neutrophils with antigen presenting cell features (hybrid TANs) in early- stage human lung cancer. Cancer Cell (2016) 30:120-35. doi: 10.1016/j.ccell.2016.06.001

179. Robertson AL, Holmes GR, Bojarczuk AN, Burgon J, Loynes CA, Chimen $\mathrm{M}$, et al. A zebrafish compound screen reveals modulation of neutrophil reverse migration as an anti-inflammatory mechanism. Sci Transl Med. (2014) 6:225-9. doi: 10.1126/scitranslmed.3007672

180. Tauzin S, Starnes TW, Becker FB, Lam P Ying, Huttenlocher A. Redox and Src family kinase signaling control leukocyte wound attraction and neutrophil reverse migration. J Cell Biol. (2014) 207:589-98. doi: $10.1083 /$ jcb. 201408090

181. Colom B, Bodkin JV, Beyrau M, Woodfin A, Ody C, Rourke C, et al. Neutrophil elastase axis drives neutrophil reverse transendothelial cell migration in vivo. Immunity (2015) 42:1075-86. doi: 10.1016/j.immuni.2015.05.010

182. Lerman I, Hammes SR. Neutrophil elastase in the tumor microenvironment. Steroids (2018) 133:96-101. doi: 10.1016/j.steroids.2017.11.006

183. Punt S, Fleuren GJ, Kritikou E, Lubberts E, Trimbos JB, Jordanova ES, et al. Angels and demons: Th17 cells represent a beneficial response, while neutrophil IL-17 is associated with poor prognosis in squamous cervical cancer. Oncoimmunology (2015) 4:984539. doi: 10.4161/2162402X.2014.984539

184. Bronte V, Brandau S, Chen SH, Colombo MP, Frey AB, Greten $\mathrm{TF}$, et al. Recommendations for myeloid-derived suppressor cell nomenclature and characterization standards. Nat Commun. (2016) 7:12150. doi: $10.1038 /$ ncomms 12150

185. Movahedi K, Guilliams M, Van Den Bossche J, Van Den Bergh R, Beschin A, De Baetselier P, et al. Identification of discrete tumor-induced myeloidderived suppressor cell subpopulations with distinct $\mathrm{T}$ cell-suppressive activity. Blood (2008) 111:4233-44. doi: 10.1182/blood-2007-07-099226

186. Schouppe E, Mommer C, Movahedi K, Laoui D, Morias Y, Gysemans C, et al. Tumor-induced myeloid-derived suppressor cell subsets exert either inhibitory or stimulatory effects on distinct CD8+ T-cell activation events. Eur I Immunol. (2013) 43:2930-42. doi: 10.1002/eji.201343349

187. Dorhoi A, Du Plessis N. Monocytic myeloid-derived suppressor cells in chronic infections. Front Immunol. (2018) 8:1895. doi: 10.3389/fimmu.2017.01895

188. Iacobaeus E, Douagi I, Jitschin R, Marcusson-Ståhl M, Törnqvist Andrén A, Gavin C, et al. Phenotypic and functional alterations of myeloidderived suppressor cells during the disease course of multiple sclerosis. Immunol Cell Biol. (2018) 96:820-30. doi: 10.1111/imcb.12042

189. Salminen A, Kaarniranta K, Kauppinen A. The potential importance of myeloid-derived suppressor cells (MDSCs) in the pathogenesis of Alzheimer's disease. Cell Mol Life Sci. (2018) 75:3099-120. doi: 10.1007/s00018-018-2844-6

190. Van Ginderachter JA, Beschin A, De Baetselier P, Raes G. Myeloid-derived suppressor cells in parasitic infections. Eur J Immunol. (2010) 40:2976-85. doi: 10.1002/eji.201040911

191. Gabrilovich DI, Ostrand-Rosenberg S, Bronte V. Coordinated regulation of myeloid cells by tumours. Nat Rev Immunol. (2012) 12:253-68. doi: $10.1038 /$ nri3175

192. Ugel S, Peranzoni E, Desantis G, Chioda M, Walter S, Weinschenk T, et al. Immune tolerance to tumor antigens occurs in a specialized environment of the spleen. Cell Rep. (2012) 2:628-39. doi: 10.1016/j.celrep.2012.08.006

193. Marigo I, Bosio E, Solito S, Mesa C, Fernandez A, Dolcetti L, et al. Tumor-induced tolerance and immune suppression depend on the C/EBP $\beta$ transcription factor. Immunity (2010) 32:790-802. doi: 10.1016/j.immuni.2010.05.010

194. Maenhout SK, Van Lint S, Emeagi PU, Thielemans K, Aerts JL. Enhanced suppressive capacity of tumor-infiltrating myeloid-derived suppressor cells 
compared with their peripheral counterparts. Int J Cancer (2014) 134:107790. doi: $10.1002 / \mathrm{ijc} .28449$

195. Zhang S, Ma X, Zhu C, Liu L, Wang G, Yuan X. The role of myeloid-derived suppressor cells in patients with solid tumors: a meta-analysis. PLoS ONE (2016) 11:e0164514. doi: 10.1371/journal.pone.0164514

196. Yang L, DeBusk LM, Fukuda K, Fingleton B, Green-Jarvis B, Shyr Y, et al. Expansion of myeloid immune suppressor $\mathrm{Gr}+\mathrm{CD} 11 \mathrm{~b}+$ cells in tumorbearing host directly promotes tumor angiogenesis. Cancer Cell (2004) 6:409-21. doi: 10.1016/j.ccr.2004.08.031

197. Yan HH, Pickup M, Pang Y, Gorska AE, Li Z, Chytil A, et al. Gr$1+\mathrm{CD} 11 \mathrm{~b}+$ myeloid cells tip the balance of immune protection to tumor promotion in the premetastatic lung. Cancer Res. (2010) 70:6139-49. doi: 10.1158/0008-5472.CAN-10-0706

198. Di Mitri D, Toso A, Chen JJ, Sarti M, Pinton S, Jost TR, et al. Tumourinfiltrating Gr-1 + myeloid cells antagonize senescence in cancer. Nature (2014) 515:134-37. doi: 10.1038/nature13638

199. Dolcetti L, Peranzoni E, Ugel S, Marigo I, Gomez AF, Mesa C, et al. Hierarchy of immunosuppressive strength among myeloid-derived suppressor cell subsets is determined by GM-CSF. Eur J Immunol. (2010) 40:22-35. doi: 10.1002/eji.200939903

200. Molon B, Ugel S, Del Pozzo F, Soldani C, Zilio S, Avella D, et al. Chemokine nitration prevents intratumoral infiltration of antigen-specific T cells. J Exp Med. (2011) 208:1949-62. doi: 10.1084/jem.20101956

201. Ramachandran IR, Condamine T, Lin C, Herlihy SE, Garfall A, Vogl DT, et al. Bone marrow PMN-MDSCs and neutrophils are functionally similar in protection of multiple myeloma from chemotherapy. Cancer Lett. (2016) 371:117-24. doi: 10.1016/j.canlet.2015.10.040

202. Vetsika EK, Koinis F, Gioulbasani M, Aggouraki D, Koutoulaki A, Skalidaki E, et al. A circulating subpopulation of monocytic myeloid-derived suppressor cells as an independent prognostic/predictive factor in untreated non-small lung cancer patients. J Immunol Res. (2014) 2014:659294. doi: $10.1155 / 2014 / 659294$

203. Meyer C, Cagnon L, Costa-Nunes CM, Baumgaertner P, Montandon N, Leyvraz L, et al. Frequencies of circulating MDSC correlate with clinical outcome of melanoma patients treated with ipilimumab. Cancer Immunol Immunother. (2014) 63:247-57. doi: 10.1007/s00262-013-1508-5

204. Sica A, Massarotti M. Myeloid suppressor cells in cancer and autoimmunity. J Autoimmun. (2017) 85:117-25. doi: 10.1016/j.jaut.2017.07.010

205. Kumar V, Patel S, Tcyganov E, Gabrilovich DI. The nature of myeloid-derived suppressor cells in the tumor microenvironment. Trends Immunol. (2016) 37:208-20. doi: 10.1016/j.it.2016.01.004

206. Atretkhany K-SN, Drutskaya MS. Myeloid-derived suppressor cells and proinflammatory cytokines as targets for cancer therapy. Biochemistry (2016) 81:1274-83. doi: $10.1134 /$ S0006297916110055

207. Zoso A, Mazza EMC, Bicciato S, Mandruzzato S, Bronte V, Serafini P, et al. Human fibrocytic myeloid-derived suppressor cells express IDO and promote tolerance via Treg-cell expansion. Eur J Immunol. (2014) 44:330719. doi: $10.1002 /$ eji.201444522

208. Sakuishi K, Jayaraman P, Behar SM, Anderson AC, Kuchroo VK. Emerging Tim-3 functions in antimicrobial and tumor immunity. Trends Immunol. (2011) 32:345-9. doi: 10.1016/j.it.2011.05.003

209. Li H, Han Y, Guo Q, Zhang M, Cao X. Cancer-expanded myeloid-derived suppressor cells induce anergy of NK cells through membrane-bound TGFbeta 1. J Immunol. (2009) 182:240-9. doi: 10.4049/jimmunol.182.1.240

210. Corzo CA, Cotter MJ, Cheng P, Cheng F, Kusmartsev S, Sotomayor E, et al. Mechanisms regulating reactive oxygen species in tumor induced myeloidderived suppressor cells: MDSC and ROS in cancer. J Immunol. (2009) 182:5693-701. doi: 10.4049/jimmunol.0900092

211. Nagaraj S, Gupta K, Pisarev V, Kinarsky L, Sherman S, Kang L, et al. Altered recognition of antigen is a novel mechanism of $\mathrm{CD} 8+\mathrm{T}$ cell tolerance in cancer. Nat Med. (2007) 13:828-35. doi: 10.1038/nm1609

212. Yu J, Du W, Yan F, Wang Y, Li H, Cao S, et al. Myeloid-derived suppressor cells suppress antitumor immune responses through ido expression and correlate with lymph node metastasis in patients with breast cancer. $J$ Immunol. (2013) 190:3783-97. doi: 10.4049/jimmunol.1390024

213. Gielen PR, Schulte BM, Kers-Rebel ED, Verrijp K, Bossman SAJFH, Ter Laan $M$, et al. Elevated levels of polymorphonuclear myeloid-derived suppressor cells in patients with glioblastoma highly express S100A8/9 and arginase and suppress T cell function. Neuro Oncol. (2016) 18:1253-64. doi: 10.1093/neuonc/now034

214. Cheng P, Corzo CA, Luetteke N, Yu B, Nagaraj S, Bui MM, et al. Inhibition of dendritic cell differentiation and accumulation of myeloidderived suppressor cells in cancer is regulated by S100A9 protein. J Exp Med. (2008) 205:2235-49. doi: 10.1084/jem.20080132

215. Sinha P, Okoro C, Foell D, Freeze HH, Ostrand-Rosenberg S, Srikrishna G. Proinflammatory S100 proteins regulate the accumulation of myeloid-derived suppressor cells. J Immunol. (2008) 181:4666-75. doi: 10.4049/jimmunol.181.7.4666

216. Sasso MS, Lollo G, Pitorre M, Solito S, Pinton L, Valpione S, et al. Low dose gemcitabine-loaded lipid nanocapsules target monocytic myeloid-derived suppressor cells and potentiate cancer immunotherapy. Biomaterials (2016) 96:47-62. doi: 10.1016/j.biomaterials.2016.04.010

217. Vincent J, Mignot G, Chalmin F, Ladoire S, Bruchard M, Chevriaux A, et al. 5-Fluorouracil selectively kills tumor-associated myeloid-derived suppressor cells resulting in enhanced $\mathrm{T}$ cell-dependent antitumor immunity. Cancer Res. (2010) 70:3052-61. doi: 10.1158/0008-5472.CAN-09-3690

218. Huang X, Cui S, Shu Y. Cisplatin selectively downregulated the frequency and immunoinhibitory function of myeloid-derived suppressor cells in a murine B16 melanoma model. Immunol Res. (2016) 64:160-70. doi: $10.1007 / \mathrm{s} 12026-015-8734-1$

219. Qin H, Lerman B, Sakamaki I, Wei G, Cha S, Rao SS, et al. Generation of a novel therapeutic peptide that depletes MDSC in tumor-bearing mice. Nat Med. (2014) 20:676-81. doi: 10.1038/nm.3560

220. Espagnolle N, Barron P, Mandron M, Blanc I, Bonnin J, Agnel M, et al. Specific inhibition of the VEGFR-3 tyrosine kinase by SAR131675 reduces peripheral and tumor associated immunosuppressive myeloid cells. Cancers (2014) 6:472-90. doi: 10.3390/cancers6010472

221. Stiff A, Trikha P, Wesolowski R, Kendra K, Hsu V, Uppati S, et al. Myeloidderived suppressor cells express Bruton's tyrosine kinase and can be depleted in tumor bearing hosts by ibrutinib treatment HHS Public Access. Cancer Res. (2016) 15:2125-36. doi: 10.1158/0008-5472.CAN-15-1490

222. Lee BR, Kwon BE, Hong EH, Shim A, Song JH, Kim HM, et al. Interleukin-10 attenuates tumour growth by inhibiting interleukin-6/signal transducer and activator of transcription 3 signalling in myeloid-derived suppressor cells. Cancer Lett. (2016) 381:156-64. doi: 10.1016/j.canlet.2016.07.012

223. Foubert P, Kaneda MM, Varner JA. PI3K $\gamma$ activates integrin $\alpha_{4}$ and promotes immune suppressive myeloid cell polarization during tumor progression. Cancer Immunol Res. (2017) 5:957-68. doi: 10.1158/2326-6066.CIR17-0143

224. Dominguez GA, Condamine T, Mony S, Hashimoto A, Wang F, Liu Q, et al. Selective targeting of myeloid-derived suppressor cells in cancer patients using DS-8273a, an agonistic TRAIL-R2 antibody. Clin Cancer Res. (2017) 23:2942-50. doi: 10.1158/1078-0432.CCR-16-1784

225. Guislain A, Gadiot J, Kaiser A, Jordanova ES, Broeks A, Sanders J, et al. Sunitinib pretreatment improves tumor-infiltrating lymphocyte expansion by reduction in intratumoral content of myeloid-derived suppressor cells in human renal cell carcinoma. Cancer Immunol Immunother. (2015) 64:124150. doi: 10.1007/s00262-015-1735-Z

226. Kim SH, Li M, Trousil S, Zhang Y, Pasca di Magliano M, Swanson KD, et al. Phenformin inhibits myeloid-derived suppressor cells and enhances the antitumor activity of PD-1 blockade in melanoma. J Invest Dermatol. (2017) 137:1740-8. doi: 10.1016/j.jid.2017.03.033

227. Zhu Y, Knolhoff BL, Meyer MA, Nywening TM, Brian L, Luo J, et al. CSF1/CSF1R blockade reprograms tumor-infiltrating macrophages and improves response to $\mathrm{T}$ cell checkpoint immunotherapy in pancreatic cancer models. Cancer Res. (2014) 74:5057-69. doi: 10.1158/0008-5472.CAN-13-3723

228. Zhang QQ, Hu XW, Liu YL, Ye ZJ, Gui YH, Zhou DL, et al. CD11b deficiency suppresses intestinal tumor growth by reducing myeloid cell recruitment. Sci Rep. (2015) 5:1-12. doi: 10.1038/srep15948

229. Kim K, Skora AD, Li Z, Liu Q, Tam AJ, Blosser RL, et al. Eradication of metastatic mouse cancers resistant to immune checkpoint blockade by suppression of myeloid-derived cells. Proc Natl Acad Sci USA. (2014) 111:11774-9. doi: 10.1073/pnas.1410626111

230. Califano JA, Khan Z, Noonan KA, Rudraraju L, Wang H, Goodman S, et al. Tadalafil augments tumor specific immunity in patients with head 
and neck squamous cell carcinoma. Clin Cancer Res. (2015) 21:30-8. doi: 10.1158/1078-0432.CCR-14-1716

231. Condamine T, Kumar V, Ramachandran IR, Youn J, Celis E, Finnberg $\mathrm{N}$, et al. ER stress regulates myeloid-derived suppressor cell fate through TRAIL-R - mediated apoptosis. J Clin Invest. (2014) 124:2626-39. doi: $10.1172 / J C I 74056$

232. Varricchi G, Galdiero MR, Loffredo S, Marone G, Iannone R, Marone G, et al. Are mast cells MASTers in cancer? Front Immunol. (2017) 8:424. doi: 10.3389/fimmu.2017.00424

233. Yang Z, Zhang B, Li D, Lv M, Huang C, Shen GX, et al. Mast cells mobilize myeloid-derived suppressor cells and Treg cells in tumor microenvironment via IL-17 pathway in murine hepatocarcinoma model. PLoS ONE (2010) 5:e8922. doi: 10.1371/journal.pone.0008922

234. Lee M, Park C-S, Lee Y-R, Im S-A, Song S, Lee C-K. Resiquimod, a TLR7/8 agonist, promotes differentiation of myeloid-derived suppressor cells into macrophages and dendritic cells. Arch Pharm Res. (2014) 37:1234-40. doi: 10.1007/s12272-014-0379-4

235. Spinetti T, Spagnuolo L, Mottas I, Secondini C, Treinies M, Rüegg C, et al. TLR7-based cancer immunotherapy decreases intratumoral myeloid-derived suppressor cells and blocks their immunosuppressive function. Oncoimmunology (2016) 5:e1230578. doi: 10.1080/2162402X.2016. 1230578

236. Shayan G, Kansy BA, Gibson SP, Srivastava RM, Bryan JK, Bauman JE, et al. Phase Ib study of immune biomarker modulation with neoadjuvant cetuximab and TLR8 stimulation in head and neck cancer to overcome suppressive myeloid signals. Clin Cancer Res. (2018) 24:62-72. doi: 10.1158/1078-0432.CCR-17-0357

237. Wang J, Shirota Y, Bayik D, Shirota H, Tross D, Gulley JL, et al. Effect of TLR agonists on the differentiation and function of human monocytic myeloid-derived suppressor cells. J Immunol. (2015) 194:421521. doi: 10.4049/jimmunol.1402004

238. Zambirinis CP, Levie E, Nguy S, Avanzi A, Barilla R, Xu Y, et al. TLR9 ligation in pancreatic stellate cells promotes tumorigenesis. J Exp Med. (2015) 212:2077-94. doi: 10.1084/jem.20142162

239. Shime H, Maruyama A, Yoshida S, Takeda Y, Matsumoto M, Seya T. Toll-like receptor 2 ligand and interferon- $\gamma$ suppress anti-tumor $\mathrm{T}$ cell responses by enhancing the immunosuppressive activity of monocytic myeloid-derived suppressor cells. Oncoimmunology (2018) 7:113. doi: $10.1080 / 2162402 X .2017 .1373231$

240. Chalmin F, Ladoire S, Mignot G, Vincent J, Bruchard M, Boireau W, et al. Membrane associated Hsp72 from tumor derived exosomes mediates STAT3 depedent immunosuppressive function of mouse and human myeloid derived suppressor cells. J Clin Invest. (2010) 120:467-71. doi: 10.1172/JCI40483

241. Janssen N, Speigl L, Pawelec G, Niessner H, Shipp C. Inhibiting HSP90 prevents the induction of myeloid-derived suppressor cells by melanoma cells. Cell Immunol. (2018) 327:68-76. doi: 10.1016/j.cellimm.2018.02.012
242. Albeituni SH, Ding C, Liu M, Hu X, Luo F, Kloecker G, et al. Yeastderived particulate $\beta$-glucan treatment subverts the suppression of myeloidderived suppressor cells by inducing PMN-MDSC apoptosis and MMDSC differentiation to APC in cancer. J Immunol. (2016) 196:2167-80. doi: $10.1016 /$ j.cogdev.2010.08.003

243. Yin Y, Huang X, Lynn KD, Thorpe PE. Phosphatidylserine-targeting antibody induces M1 macrophage polarization and promotes myeloidderived suppressor cell differentiation. Cancer Immunol Res. (2013) 1:25668. doi: 10.1158/2326-6066.CIR-13-0073

244. Zhou J, Donatelli SS, Gilvary DL, Tejera MM, Eksioglu EA, Chen X, et al. Therapeutic targeting of myeloid-derived suppressor cells involves a novel mechanism mediated by clusterin. Sci Rep. (2016) 6:29521. doi: $10.1038 /$ srep29521

245. Yaddanapudi K, Rendon BE, Lamont G, Kim EJ, Al Rayyan N, Richie J, et al. MIF is necessary for late-stage melanoma patient MDSC immune suppression and differentiation. Cancer Immunol Res. (2016) 4:101-12. doi: 10.1158/2326-6066.CIR-15-0070-T

246. Shen L, Sundstedt A, Ciesielski M, Miles KM, Celander M, Adelaiye R, et al. Tasquinimod modulates suppressive myeloid cells and enhances cancer immunotherapies in murine models. Cancer Immunol Res. (2015) 3:136-48. doi: 10.1158/2326-6066.CIR-14-0036

247. Du Four S, Maenhout SK, De Pierre K, Renmans D, Niclou SP, Thielemans $\mathrm{K}$, et al. Axitinib increases the infiltration of immune cells and reduces the suppressive capacity of monocytic MDSCs in an intracranial mouse melanoma model. Oncoimmunology (2015) 4:e998107. doi: 10.1080/2162402X.2014.998107

248. Gentles AJ, Newman AM, Liu CL, Bratman SV, Diehn M, West RB, et al. The prognostic landscape of genes and infiltrating immune cells across human cancers. Nat Med. (2015) 21:938-45. doi: 10.1038/ nm.3909

249. Charoentong P, Finotello F, Angelova M, Mayer C, Efremova M, Rieder D, et al. Pan-cancer immunogenomic analyses reveal genotypeimmunophenotype relationships and predictors of response to checkpoint blockade. Cell Rep. (2017) 18:248-62. doi: 10.1016/j.celrep.2016. 12.019

Conflict of Interest Statement: The authors declare that the research was conducted in the absence of any commercial or financial relationships that could be construed as a potential conflict of interest.

Copyright (c) 2018 Clappaert, Murgaski, Van Damme, Kiss and Laoui. This is an open-access article distributed under the terms of the Creative Commons Attribution License (CC BY). The use, distribution or reproduction in other forums is permitted, provided the original author (s) and the copyright owner(s) are credited and that the original publication in this journal is cited, in accordance with accepted academic practice. No use, distribution or reproduction is permitted which does not comply with these terms. 